\title{
REVISED GLOBAL MODEL OF THERMOSPHERE WINDS USING SATELLITE AND GROUND-BASED OBSERVATIONS
}

\author{
A. E. Hedin, ${ }^{1}$ M. A. Biondi, ${ }^{2}$ R. G. Burnside, ${ }^{3}$ G. Hernandez, ${ }^{4}$ R. M. Johnson, ${ }^{5}$ T. L. Killeen, ${ }^{5}$ \\ C. Mazaudier, ${ }^{6}$ J. W. Meriwether, ${ }^{7}$ J. E. Salah, ${ }^{8}$ R. J. Sica, ${ }^{9}$ R. W. Smith, ${ }^{10}$ N. W. Spencer, ${ }^{11}$ \\ V. B. Wickwar, 12 and T. S. Virdi 13
}

\begin{abstract}
Thermospheric wind data obtained from the Atmosphere Explorer E and Dynamics Explorer 2 satellites have been combined with wind data for the lower and upper thermosphere from ground-based incoherent scatter radar and Fabry-Perot optical interferometers to generate a revision (HWM90) of the HWM87 empirical model and extend its applicability to $100 \mathrm{~km}$. Comparison of the various data sets with the aid of the model shows in general remarkable agreement, particularly at mid and low latitudes. The groundbased data allow modeling of seasonal/diurnal variations, which are most distinct at mid latitudes. While solar activity variations are now included, they are found to be small and not always very clearly delineated by the current data. They are most obvious at the higher latitudes. The model describes the transition from predominately diurnal variations in the upper thermosphere to semidiurnal variations in the lower thermosphere and a transition from summer to winter flow above $140 \mathrm{~km}$ to winter to summer flow below. Significant altitude gradients in the wind are found to extend to $300 \mathrm{~km}$ at some local times and pose complications for interpretation of Fabry-Perot observations.
\end{abstract}

\section{Introduction}

The HWM87 empirical model (horizontal wind model) [Hedin et al., 1988] of upper thermosphere winds based on satellite data from DE 2 and AE-E provided a unified description of the meridional and zonal winds in a manner

1Planetary Atmospheres Branch, NASA Goddard Space Flight Center, Greenbelt, Maryland.

2Department of Physics and Astronomy, University of Pittsburgh, Pittsburgh, Pennsylvania.

${ }^{3}$ Arecibo Observatory, Arecibo, Puerto Rico.

${ }^{4}$ Graduate Program in Geophysics, University of Washington, Seattle.

5Space Physics Research Laboratory, University of Michigan, Ann Arbor.

${ }^{6}$ Centre de Recherches en Physique de l'Environnement, Saint-Maur, France.

${ }^{7}$ Air Force Geophysics Laboratory, Hanscom Air Force

Base, Bedford, Massachusetts.

${ }^{8}$ Haystack Observatory, Massachusetts Institute of Technology, Westford.

${ }^{9}$ Department of Physics, The University of Western Ontario, London, Ontario, Canada.

${ }^{10}$ Geophysical Institute, University of Alaska, Fairbanks.

11University Research Foundation, NASA Goddard Space Flight Center, Greenbelt, Maryland.

${ }^{12}$ Center for Atmospheric and Space Sciences, Utah State University, Logan.

13Physics Department, University College of Wales, Aberystwyth.

Copyright 1991 by the American Geophysical Union.

Paper number 91JA00251.

0148-0227/91/91JA-00251\$05.00 similar to the MSIS-86 model of temperature, density, and composition [Hedin, 1987]. Data were available for only a limited range of solar activities and altitudes, but it was shown that predictions for low and mid latitudes were similar to published ground-based measurements. Miller et al. [1990] have shown that winds inferred from ionosonde data are also in remarkably good agreement with HWM87.

This paper presents a revised model (designated HWM90) that incorporates ground-based data from several incoherent scatter radar and Fabry-Perot optical interferometers extending the data coverage in both solar activity and altitude. Extensive comparisons are made of the data with both the new and the older model. The basic harmonic expansions used in HWM87 have been extended to accommodate the new data. The loweraltitude limit of the model has been reduced from $220 \mathrm{~km}$ to $100 \mathrm{~km}$.

\section{Data Selection}

The primary data incorporated in this study were gathered by satellite, ground-based incoherent scatter radar, and groundbased Fabry-Perot optical instrumentation, supplemented at the lower boundary by summaries of MF/meteor radar and older rocket data. Most of the data were obtained from original data bases but were in some cases derived from published figures, models, or summary tables.

The satellite data consist of zonal winds from the wind and temperature spectrometer (WATS) [Spencer et al., 1981] and meridional winds from the Fabry-Perot interferometer (FPI) [Hays et al., 1981] on the polar-orbiting DE 2 satellite during late 1981 to early 1983 , and a mix of meridional and zonal winds from the neutral atmosphere temperature experiment (NATE) [Spencer et al., 1973] on the near-equatorial AE-E satellite during 1975 to 1978 . These data were the same as those used in generating HWM87 (except lower-altitude AE-E data are now used) and discussed in the previous paper. The WATS and FPI data from DE 2 range in altitude from 220 to $600 \mathrm{~km}$ at high solar activity. The NATE data from AE-E range in altitude from 135 to $400 \mathrm{~km}$ at low to moderate solar activities.

The incoherent scatter and Fabry-Perot data sets are summarized in Table 1. Generally, Fabry-Perot measurements are taken only during local night and assume the vertical wind is zero. Incoherent scatter $F$ region data are available for all local times, but nighttime data are expected to be less accurate than daytime data because of corrections for ambipolar diffusion, based partly on quantities estimated from models, which are more important at night. Except at high latitudes, incoherent scatter E region data are generally only reliable during daytime because of low signal levels at night. For Sondrestrom, Millstone Hill, and Arecibo, meridional winds along the magnetic meridian were derived in a uniform fashion [Wickwar, 1989] from the 1983 to 1987 incoherent scatter radar ionospheric data (the "MERWIND" tape) assuming an atomic oxygen ion-neutral collision frequency of 1.7 [Burnside et al., 1987] times the values given by Schunk and Walker [1973].

Local time average meridional and zonal winds obtained by MF/meteor radar between 90 and $111 \mathrm{~km}$ for Adelaide, Atlanta, Christchurch, Kyoto, Saskatoon, and Townsville, over varying 


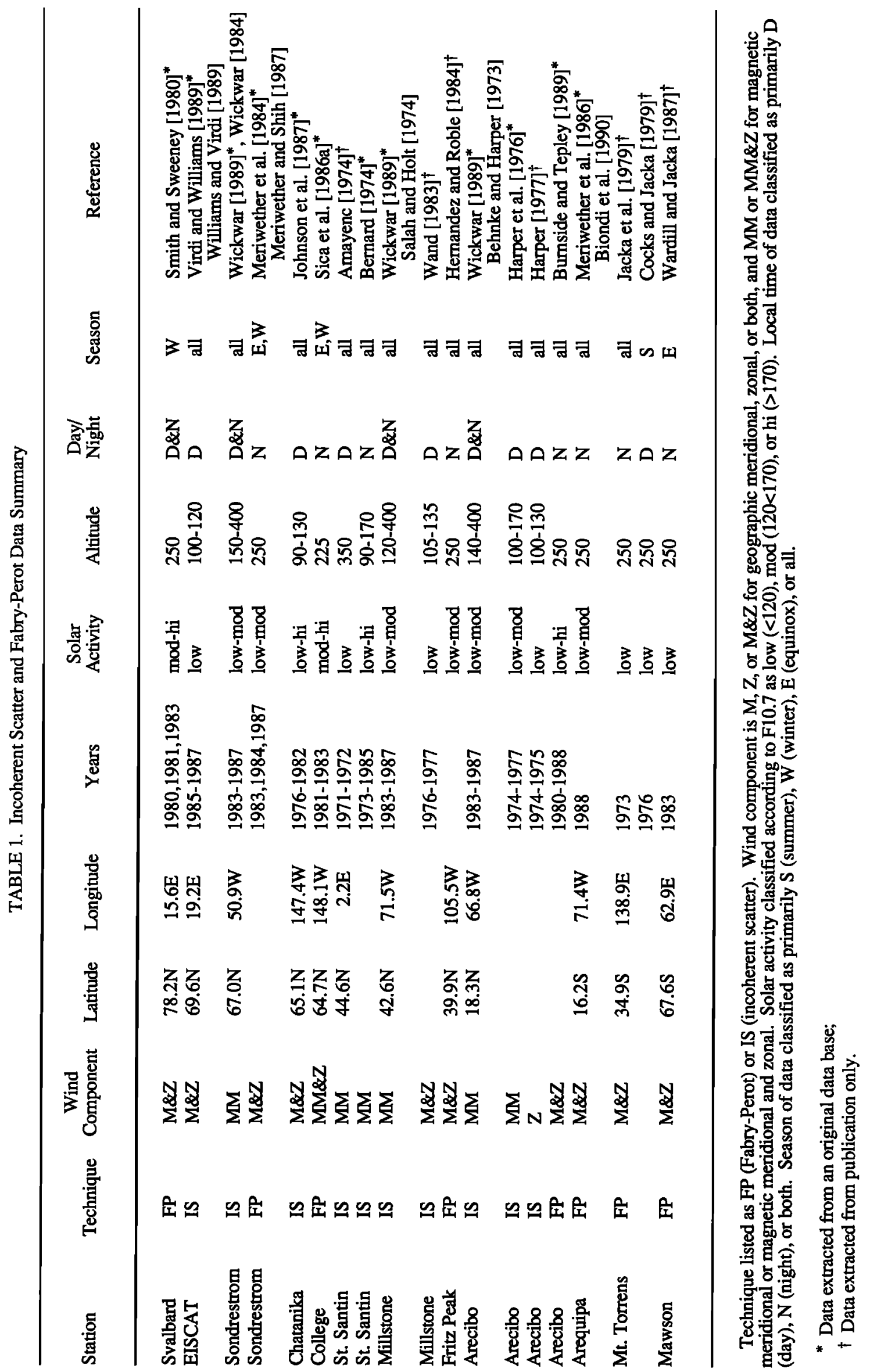


parts of the 1976 to 1984 time period, were used from tabulations by Manson et al. [1985]. Local time average meridional and zonal winds summarizing older rocket and meteor radar data in the $100-$ to $130-\mathrm{km}$ altitude range were used from tabulations by Groves [1969].

\section{Model Formulation}

The HWM90 model is an extension of the HWM87 model, which is described in considerable detail by Hedin et al. [1988]. Here only the main points will be summarized, and the principal new features described. The HWM90 model requires the user to input the day of year, time of day (UT), altitude, geographic latitude and longitude, local solar time, 3-month average and previous day value of the $10.7-\mathrm{cm}$ solar flux index, and either the daily Ap magnetic index or prescibed history of 3-hour ap indices.

The HWM87 model represented spatial (latitude and longitude or local time) variations in the thermospheric horizontal wind vector by an expansion in vector spherical harmonics [Morse and Feshbach, 1953] with each expansion coefficient represented by a Fourier series in universal time and/or day of year as appropriate. There were no altitude or solar activity variations. The expansion involves two orthogonal vector fields, the divergence $B$ field and the rotational $\mathrm{C}$ field.

In HWM90, two functional forms are used for the altitude variation. Above $200 \mathrm{~km}$ where viscosity is expected to limit altitude gradients, the altitude variations of the zonal and meridional wind components are each represented by a extension of the Bates formula [Bates, 1959] as used for thermospheric temperature profiles, which uncouples the lower bound gradient from the rate of convergence to a high-altitude asymptote:

$$
\begin{aligned}
\mathrm{u}= & \mathrm{u}_{\mathrm{inf}}+\left[\left(\mathrm{u}_{\mathrm{lb}}-\mathrm{u}_{\mathrm{inf}}\right)+\left(\mathrm{u}_{\mathrm{lb}}-\mathrm{u}_{\mathrm{inf}}+\mathrm{u}_{\mathrm{lb}}^{\prime}\right)\left(\mathrm{z}_{\mathbf{l b}}-\mathbf{z}\right) / \mathrm{H}_{\mathrm{w}}\right] \\
& * \exp \left(\left(\mathbf{z}_{\mathbf{l b}}-\mathbf{z}\right) / \mathrm{H}_{\mathrm{w}}\right)
\end{aligned}
$$

where $\mathrm{u}$ is the meridional (or zonal) wind, $\mathrm{z}$ is altitude in kilometers, $z_{l b}$ is the altitude of a lower bound $(200 \mathrm{~km}), \mathrm{H}_{\mathrm{w}}$ is a wind scale height, $u^{\prime}{ }_{b}$ is the wind gradient and $u_{l b}$ the wind value $a t z_{l b}$, and $u_{i n f}$ the asymptotic value in the high thermosphere (the exospheric value in analogy to the exospheric temperature). This formula allows specification, in general, of a wind magnitude and altitude gradient at a lower bound, an asymptotic or exospheric value, and the rate of convergence to the asymptote through a wind scale height. It is assumed that the wind varies with height on a scale similar to the atmospheric scale height in the upper thermosphere [Rishbeth, 1972], and for the present model this scale height was taken as $62.5 \mathrm{~km}$, the approximate average pressure scale height in the thermosphere from MSIS-86.

Below $200 \mathrm{~km}$ the wind profiles are represented by a cubic spline, defined by cubic polynomials between specified nodes with first and second derivatives continuous across interior nodes. The nodes were chosen to be at $200,150,130,115$, and $100 \mathrm{~km}$. The wind magnitude and altitude gradient are matched at $200 \mathrm{~km}$ with the upper thermosphere values, and in addition the altitude gradient is specified at $100 \mathrm{~km}$. The nodes were not chosen equally spaced because there is relatively little data available between 130 and $250 \mathrm{~km}$ to support a higherresolution description at present. Some example profiles from the model are shown in Figure 1. In general, wind magnitudes are smaller at lower altitudes and have sharper altitude gradients. Other details will be discussed later in this paper. Note, however, that the altitude profiles between 130 and 220 $\mathrm{km}$ may be less valid than for other altitude regions, given the paucity of data in this region, particularly for the zonal component, for which there is only the equatorial AE-E data.

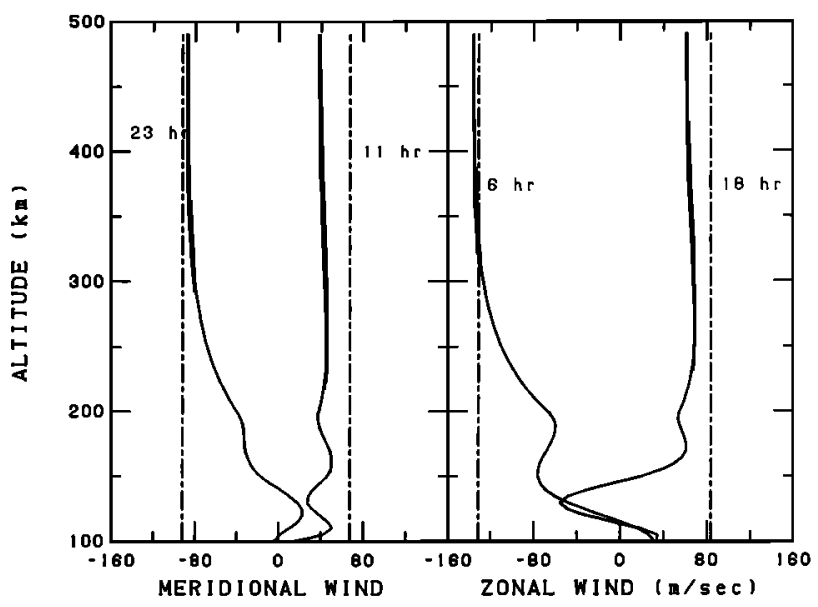

Fig. 1. Annual and longitudinal average HWM90 model (solid lines) northward meridional and eastward zonal winds versus altitude for two local times at $45^{\circ} \mathrm{N}$ latitude. Results from HWM87 are also shown (dash-dot).

The spatial and temporal variation of the wind is described by expanding the exospheric wind, the wind at each of the cubic spline nodes, and the altitude gradients at $200 \mathrm{~km}$ and $100 \mathrm{~km}$ in terms of a spherical harmonic expansion similar to that used for the HWM87 model. Because of the sparsity of data between 130 and $220 \mathrm{~km}$ and concem with providing reasonable continuity through this region, a simplification was introduced for the winds at 150 and $200 \mathrm{~km}$ and the gradient at $200 \mathrm{~km}$. These values were assumed to be basically proportional to the exospheric wind values augmented with additional semidiurnal terms. The proportionality was found to be 0.62 at $200 \mathrm{~km}$ and 0.5 at $150 \mathrm{~km}$.

The harmonic expansion formulation is modified from HWM 87 by inclusion of higher-order terms, more annual/daily variation cross terms (seasonal variations), and multipliers for solar activity variations. The terms used in this model are summarized and compared to HWM87 in Table 2. The classification into symmetrical and asymmetrical is with respect to reflection about the equator with symmetrical meaning the vector spherical harmonic term provides zonal winds which have the same direction across the equator while the meridional wind changes direction. The column value " $\mathrm{m}$ " refers to the longitudinal (or local time) harmonic content ( 0 means no longitudinal variation, 1 the first harmonic, etc.). The " $n$ " value is the latitude harmonic order and is always equal to or larger than " $m$ ". If the $n-m$ value is even, then the B field term is symmetric and the $C$ field term is asymmetric. The higher the order " $n$ " the greater the latitude variability that can be represented. Terms of order higher than those in the table were not found to be significant in fitting the present data set. In Table 2 a dash means this term is not included for this node while the quote symbol is a reminder that this node was linked to the exospheric wind values via an overall multiplier for this node.

Only the simplest solar activity dependence was considered in this model in the form of linearly scaling various groups of terms by a sum of the 81-day mean $10.7-\mathrm{cm}$ solar flux index and fraction of the daily minus mean index. This procedure is analogous to that used in modeling neutral temperature; the current data coverage is inadequate to support a more detailed description. The daily solar flux variations were marginally found to be only $10 \%$ as effective as the mean flux variations in describing wind variations. In contrast, the daily flux variations are about 30 to $50 \%$ as effective as the mean flux variations in describing total density and temperature variations 
TABLE 2a. Maximum B Field Spherical Harmonic Order (n)

\begin{tabular}{|c|c|c|c|c|c|c|c|c|c|c|}
\hline \multirow[b]{3}{*}{ Term } & \multirow[b]{3}{*}{$\mathbf{m}$} & \multirow[b]{3}{*}{ HWM87 } & \multicolumn{8}{|c|}{ B Field Parameter (Node Altitude, km) } \\
\hline & & & \multirow[b]{2}{*}{ Exosphere } & \multirow[b]{2}{*}{200} & \multirow[b]{2}{*}{150} & \multirow[b]{2}{*}{130} & \multirow[b]{2}{*}{115} & \multirow[b]{2}{*}{100} & \multicolumn{2}{|c|}{ Gradient } \\
\hline & & & & & & & & & $\overline{200}$ & 100 \\
\hline \multicolumn{11}{|l|}{ Symmetrical } \\
\hline $\begin{array}{l}\text { Time independent } \\
\text { Time independent-F10.7 } \\
\text { multiplier }\end{array}$ & $\begin{array}{l}0 \\
0\end{array}$ & $\begin{array}{l}4 \\
-\end{array}$ & $\begin{array}{l}4 \\
0\end{array}$ & $"$ & $"$ & $\begin{array}{l}2 \\
-\end{array}$ & 2 & $\begin{array}{l}4 \\
-\end{array}$ & $"$ & $\begin{array}{l}2 \\
-\end{array}$ \\
\hline Diurnal & 1 & 3 & 3 & $"$ & $"$ & 3 & 5 & 3 & $"$ & 1 \\
\hline Diurnal-semiannual & 1 & - & 3 & $"$ & $"$ & - & $=$ & - & " & - \\
\hline Diumal-Ap. & 1 & - & $=$ & - & - & 3 & 5 & - & - & - \\
\hline Semidiurnal & 2 & 2 & 6 & 6 & 2 & 4 & 4 & 2 & - & 4 \\
\hline Semidiumal-Annual & 2 & - & 2 & $"$ & $"$ & - & - & - & $"$ & - \\
\hline Semidiurnal-Ap & 2 & - & 2 & $"$ & $"$ & - & - & - & $"$ & - \\
\hline $\begin{array}{l}\text { Semidiumal-F10.7 } \\
\text { multiplier }\end{array}$ & 0 & - & 0 & $"$ & $"$ & - & - & - & $"$ & - \\
\hline Terdiurnal & 3 & 3 & 7 & $"$ & $"$ & - & - & - & $"$ & - \\
\hline Longitude & 2 & - & 6 & $"$ & $"$ & - & - & - & " & - \\
\hline Ap & 0 & 4 & 6 & $"$ & $"$ & - & 2 & - & $"$ & - \\
\hline \multicolumn{11}{|l|}{ Asymmetrical } \\
\hline Annual & 0 & 1 & 1 & $"$ & $"$ & - & 1 & 3 & $"$ & 1 \\
\hline Diumal & 1 & - & 2 & $"$ & " & - & - & - & $"$ & - \\
\hline Diurnal-annual & 1 & - & 4 & $"$ & $"$ & - & - & - & $"$ & - \\
\hline Semidiurnal & 2 & - & 7 & $"$ & " & - & - & - & $"$ & - \\
\hline Semidiumal-annual & 2 & - & 3 & 3 & 3 & 3 & - & 3 & $"$ & - \\
\hline $\begin{array}{l}\text { Semidiurnal-F10.7 } \\
\text { multiplier }\end{array}$ & 0 & - & 0 & $"$ & $"$ & - & - & - & " & 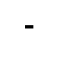 \\
\hline Longitude & 1 & 2 & 2 & $"$ & " & - & - & - & $"$ & - \\
\hline Longitude-Ap & 1 & - & 6 & " & " & - & - & - & $"$ & - \\
\hline UT & 0 & - & 5 & $"$ & $"$ & - & - & - & $"$ & - \\
\hline UT-Ap & 0 & 3 & 3 & $"$ & " & - & - & - & $"$ & - \\
\hline
\end{tabular}

See text discussion.

in MSIS-86, although the effect on the pressure gradient force is more complex and not readily generalized.

The determination of the harmonic coefficients for the various nodes of the wind profile is accomplished by a least squares fit to selected subsets of the data. As in HWM87, magnetic activity terms were determined for the daily Ap and 3- hour ap indices independently. For the 200 - to $350-\mathrm{km}$ altitude region where there is the most overlap of various data sets, the average departures and standard deviations of the more complete data sets from the model, subdivided by broad latitude regions, are given in Table 3 for days with Ap<20. Data extracted from publications have considerably less spread in their data to model differences than data from original data bases. The data to model spread is also higher at high latitudes where both the systematic and random variations are larger. Figures 2 and 3 illustrate the differences between data and model as a function of local time for the various data sources. The data spread indicated by the error bars is a combination of modeling errors and experimental errors. In these and other plots for this altitude region the radar data (except for St. Santin) were limited to 200 to $300 \mathrm{~km}$ to provide the most consistent comparison. The model wind corresponding to a given data point is always calculated by combining meridional and zonal winds if necessary when the measurement is not in the geographic northward or eastward direction. Although the longitude and UT terms included in the model do allow for systematic differences between observing sites, some systematic differences remain, particularly at high latitudes. Winds in the lower thermosphere are also highly variable due, in part, to day to day changes in apparent tidal amplitudes which are not included in the model.

\section{Model Examples and Comparisons}

\subsection{Dailv Variations at High Altitude}

For altitudes between 200 and $350 \mathrm{~km}$, where there are overlapping ground-based and satellite meridional wind measurements, it is interesting to bin the data in local time and compare with the average model winds calculated for the conditions of the data. This displays the actual measured daily variation for the various data sets and in a general way how the model varies with local time. However, the intercomparison between individual data sets in this type of presentation can be somewhat misleading because some data are reported in geographic coordinates and some in magnetic, although in most cases this is not a major difference. Also, the data coverage for various local times is not uniform in season and other parameters, and thus the model curve does not necessarily 
TABLE 2b. Maximum C Field Spherical Harmonic Order (n)

\begin{tabular}{|c|c|c|c|c|c|c|c|c|c|c|}
\hline \multirow[b]{3}{*}{ Term } & \multirow[b]{3}{*}{$\mathbf{m}$} & \multirow[b]{3}{*}{ HWM87 } & \multicolumn{8}{|c|}{ C Field Parameter (Node Altitude, km) } \\
\hline & & & \multirow[b]{2}{*}{ Exosphere } & \multirow[b]{2}{*}{200} & \multirow[b]{2}{*}{150} & \multirow[b]{2}{*}{130} & \multirow[b]{2}{*}{115} & \multirow[b]{2}{*}{100} & \multicolumn{2}{|c|}{ Gradient } \\
\hline & & & & & & & & & 200 & 100 \\
\hline \multicolumn{11}{|l|}{ Symmetrical } \\
\hline Time independent & $\mathbf{0}$ & 5 & 5 & $"$ & $"$ & 3 & 3 & 3 & $"$ & 3 \\
\hline $\begin{array}{l}\text { Time independent-F10.7 } \\
\text { multiplier }\end{array}$ & $\mathbf{0}$ & - & 0 & $"$ & " & - & - & - & " & - \\
\hline Semiannual & 0 & - & - & $\overline{-}$ & $\overline{-}$ & - & 1 & 1 & - & $\overline{2}$ \\
\hline Diumal & 1 & 8 & 8 & $"$ & $"$ & 6 & 6 & 2 & $"$ & 2 \\
\hline Diurnal-F10.7 multiplier & 0 & - & $\mathbf{0}$ & " & " & - & $\overline{-}$ & - & $"$ & - \\
\hline Diumal-Ap & 1 & - & - & $\overline{-}$ & - & 2 & 3 & - & $"$ & 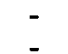 \\
\hline Diumal-Ap multiplier & $\mathbf{0}$ & $\mathbf{0}$ & $\mathbf{0}$ & $"$ & $"$ & $\bar{z}$ & $\bar{z}$ & $\bar{z}$ & $"$ & 5 \\
\hline Semidiurnal & 2 & - & 5 & 7 & 3 & 5 & 5 & 3 & " & 5 \\
\hline Semidiumal-Ap & 2 & - & 5 & $"$ & " & - & - & - & " & - \\
\hline Terdiurnal & 3 & - & 8 & $"$ & $"$ & - & - & - & $"$ & - \\
\hline Longitude & 2 & - & 9 & $"$ & " & - & - & - & " & - \\
\hline $\begin{array}{l}\text { Longitude-asymmetric } \\
\text { multiplier }\end{array}$ & 0 & - & 1 & $"$ & $"$ & - & - & - & " & - \\
\hline Longitude-F10.7 multiplier & 0 & - & 0 & $"$ & $"$ & - & - & - & " & - \\
\hline Ap & 0 & 3 & 5 & $"$ & $"$ & - & - & - & " & 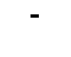 \\
\hline \multicolumn{10}{|l|}{ Asymmetrical } & \\
\hline Time independent & $\mathbf{0}$ & 12 & 12 & $"$ & $"$ & - & - & - & $"$ & - \\
\hline $\begin{array}{l}\text { Time independent-F10.7 } \\
\text { multiplier }\end{array}$ & 0 & - & 0 & $"$ & " & - & - & - & $"$ & - \\
\hline Annual & $\mathbf{0}$ & 2 & 2 & $"$ & $"$ & 2 & 4 & 2 & " & - \\
\hline Annual-F10.7 multiplier & 0 & - & 0 & " & $"$ & - & - & - & $"$ & - \\
\hline Diurnal & 1 & 9 & 9 & $"$ & $"$ & - & - & - & " & - \\
\hline Diumal-annual & 1 & 1 & 3 & $"$ & " & - & - & - & $"$ & - \\
\hline Diurnal-F10.7 multiplier & 0 & - & 0 & $"$ & $"$ & - & - & - & $"$ & 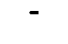 \\
\hline $\begin{array}{l}\text { Diumal-annual-F10.7 } \\
\text { multiplier }\end{array}$ & 0 & - & $\mathbf{0}$ & $"$ & $"$ & - & - & - & $"$ & - \\
\hline Semidiurnal & 2 & 8 & 8 & " & $"$ & 0 & - & - & $"$ & - \\
\hline Semidiurnal-annual & 2 & 2 & 4 & 2 & 2 & 2 & - & 2 & " & - \\
\hline Terdiurnal-annual & 3 & - & 5 & " & $"$ & - & - & - & $"$ & - \\
\hline Longitude & 1 & 9 & 9 & " & " & - & - & - & $"$ & - \\
\hline $\begin{array}{l}\text { Longitude-asymmetric } \\
\text { multiplier }\end{array}$ & $\mathbf{0}$ & - & 1 & " & " & - & - & - & $"$ & - \\
\hline Longitude-F10.7 multiplier & $\mathbf{0}$ & - & $\mathbf{0}$ & $"$ & " & - & - & - & $"$ & - \\
\hline Longitude-Ap multiplier & $\mathbf{0}$ & - & $\mathbf{0}$ & $"$ & " & - & - & - & " & 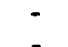 \\
\hline $\mathrm{UT}^{\circ}$ & $\mathbf{0}$ & 10 & 12 & $"$ & $"$ & - & - & - & $"$ & - \\
\hline UT-longitude & 2 & 10 & 10 & $"$ & $"$ & - & - & - & $"$ & - \\
\hline UT-F10.7 multiplier & $\mathbf{0}$ & - & $\mathbf{0}$ & " & " & - & - & - & " & - \\
\hline UT-Ap multiplier & $\mathbf{0}$ & - & $\mathbf{0}$ & " & $"$ & - & - & - & $"$ & - \\
\hline
\end{tabular}

show local time variations for average or fixed conditions. Data overlap in altitude for zonal winds is poorer than for meridional, since the DE 2 mass spectrometer data are predominantly above $300 \mathrm{~km}$.

High-latitude meridional wind data for three seasons (summer refers to the June solstice for northern hemisphere data and December solstice for southem hemisphere data) are compared in Figure 4 with model winds calculated for the conditions of the data. In the northern hemisphere there is a fair degree of overlap between the radar (Sondrestrom), ground-based optical (Sondrestrom, Svalbard, and College), and satellite (DE 2) data. The revised model generally fits the total data better than HWM87, particularly where satellite data are lacking at midday. The DE satellite data do have a slightly larger diumal variation than the ground-based data, and thus are more like HWM87. The College Fabry-Perot data are least well represented by the model, being more northward on average than the model and with a smaller diumal variation. The summer evening model winds are not as southward as observed by the Sondrestrom radar. There does not appear to be a similar difference in the southern summer or northern winter. Note, however, that the nighttime radar winds are systematically more southward than the Fabry-Perot observations for the same site in other seasons. Part of the 
TABLE 3a. Meridional Wind Differences From HWM90 Between 200 and $350 \mathrm{~km}$ For the Northern Hemisphere

\begin{tabular}{|c|c|c|c|c|c|c|c|c|c|}
\hline \multirow[b]{2}{*}{ Data Set } & \multicolumn{3}{|c|}{$\begin{array}{l}\text { Latitude } \\
60^{\circ} \mathrm{N} \text { to } 90^{\circ} \mathrm{N}\end{array}$} & \multicolumn{3}{|c|}{$\begin{array}{l}\text { Latitude } \\
30^{\circ} \mathrm{N} \text { to } 60^{\circ} \mathrm{N}\end{array}$} & \multicolumn{3}{|c|}{$\begin{array}{l}\text { Latitude } \\
0^{\circ} \text { to } 30^{\circ} \mathrm{N}\end{array}$} \\
\hline & avg & sd & pts & $\overline{\text { avg }}$ & sd & pts & $\overline{\text { avg }}$ & sd & $\overline{\text { pts }}$ \\
\hline $\begin{array}{l}\text { DE } 2 \text { FP } \\
\text { Sondrestrom FP } \\
\text { Sondrestrom IS } \\
\text { Svalbard FP } \\
\text { College FP }\end{array}$ & $\begin{array}{r}-6 \\
32 \\
-27 \\
11 \\
52\end{array}$ & $\begin{array}{r}99 \\
127 \\
147 \\
110 \\
114\end{array}$ & $\begin{array}{r}3466 \\
1635 \\
7683 \\
2949 \\
588\end{array}$ & & & & & & \\
\hline $\begin{array}{l}\text { DE } 2 \text { FP } \\
\text { Millstone Hill IS } \\
\text { St. Santin IS } \\
\text { Fritz Peak FP }\end{array}$ & & & & $\begin{array}{r}-9 \\
-4 \\
0 \\
-3\end{array}$ & $\begin{array}{l}43 \\
72 \\
18 \\
28\end{array}$ & $\begin{array}{r}1425 \\
11917 \\
768 \\
289\end{array}$ & & & \\
\hline $\begin{array}{l}\text { DE 2 FP } \\
\text { Arecibo IS } \\
\text { Arecibo FP } \\
\text { AE-E MS }\end{array}$ & & & & & & & $\begin{array}{r}0 \\
-9 \\
1 \\
2\end{array}$ & $\begin{array}{l}39 \\
50 \\
47 \\
54\end{array}$ & $\begin{array}{r}539 \\
7235 \\
2077 \\
9637\end{array}$ \\
\hline
\end{tabular}

Here avg is average, sd is standard deviation, and pts is points. FP is Fabry-Perot, IS is incoherent scatter radar, and MS is mass spectrometer.

TABLE 3b. Meridional Wind Differences From HWM90 Between 200 and $350 \mathrm{~km}$ For the Southern Hemisphere

\begin{tabular}{|c|c|c|c|c|c|c|c|c|c|}
\hline \multirow[b]{2}{*}{ Data Set } & \multicolumn{3}{|c|}{$\begin{array}{l}\text { Latitude } \\
60^{\circ} \mathrm{S} \text { to } 90^{\circ} \mathrm{S}\end{array}$} & \multicolumn{3}{|c|}{$\begin{array}{l}\text { Latitude } \\
30^{\circ} \mathrm{S} \text { to } 60^{\circ} \mathrm{S}\end{array}$} & \multicolumn{3}{|c|}{$\begin{array}{l}\text { Latitude } \\
0^{\circ} \text { to } 30^{\circ} \mathrm{S}\end{array}$} \\
\hline & $\overline{\text { avg }}$ & sd & pts & $\overline{\text { avg }}$ & sd & pts & $\overline{\text { avg }}$ & sd & $\overline{\text { pts }}$ \\
\hline $\begin{array}{l}\text { DE } 2 \text { FP } \\
\text { Mawson FP }\end{array}$ & $\begin{array}{r}4 \\
-28\end{array}$ & $\begin{array}{l}97 \\
61\end{array}$ & $\begin{array}{r}2563 \\
26\end{array}$ & & & & & & \\
\hline $\begin{array}{l}\text { DE } 2 \text { FP } \\
\text { Mt. Torrens }\end{array}$ & & & & $\begin{array}{r}-5 \\
4\end{array}$ & $\begin{array}{l}51 \\
41\end{array}$ & $\begin{array}{r}1651 \\
34\end{array}$ & & & \\
\hline $\begin{array}{l}\text { DE } 2 \text { FP } \\
\text { Arequipa FP } \\
\text { AE-E MS }\end{array}$ & & & & & & & $\begin{array}{r}1 \\
0 \\
14\end{array}$ & $\begin{array}{l}49 \\
71 \\
57\end{array}$ & $\begin{array}{r}594 \\
1189 \\
11121\end{array}$ \\
\hline
\end{tabular}

difference between radar and Fabry-Perot could be due to the uncertainty in the knowledge of the neutral-ion collision frequency. In the southern hemisphere, the Mawson optical data are more southward in the evening than the satellite data. In general, data coverage is very sparse in the southern hemisphere and totally lacking in winter.

Because there are greater differences in observing conditions for the high northern latitude data than for lower latitudes, Figure 5 shows data for all seasons from the different sources each compared separately with the wind models. This figure shows that the model does adjust in part for the different observation conditions at each site.
Mid-latitude meridional wind data for three seasons are compared in Figure 6. In the northern hemisphere, agreement between the radar (Millstone Hill and St. Santin), ground-based optical (Fritz Peak), and satellite (DE 2) data sets is rather good. There is a systematic seasonal change, most evident in the early evening hours, that is well represented by the HWM90 model. The satellite data did not have sufficient coverage to detect this variation, and it is not present in HWM87. Although southern hemisphere data are again sparse, there is fairly good agreement between the Mt. Torrens optical and DE 2 satellite data and with both HWM90 and HWM87.

Low-latitude meridional wind data for three seasons are 
TABLE 3c. Zonal Wind Differences From HWM90 Between 200 and $350 \mathrm{~km}$ For the Northern Hemisphere

\begin{tabular}{|c|c|c|c|c|c|c|c|c|c|}
\hline \multirow[b]{2}{*}{ Data Set } & \multicolumn{3}{|c|}{$\begin{array}{l}\text { Latitude } \\
60^{\circ} \mathrm{N} \text { to } 90^{\circ} \mathrm{N}\end{array}$} & \multicolumn{3}{|c|}{$\begin{array}{l}\text { Latitude } \\
30^{\circ} \mathrm{N} \text { to } 60^{\circ} \mathrm{N}\end{array}$} & \multicolumn{3}{|c|}{$\begin{array}{l}\text { Latitude } \\
0^{\circ} \text { to } 30^{\circ} \mathrm{N}\end{array}$} \\
\hline & $\overline{\text { avg }}$ & sd & pts & $\overline{\text { avg }}$ & sd & pts & $\overline{\operatorname{avg}}$ & $\mathrm{sd}$ & $\overline{p t s}$ \\
\hline $\begin{array}{l}\text { DE } 2 \text { MS } \\
\text { Sondrestrom FP } \\
\text { Svalbard FP } \\
\text { College FP }\end{array}$ & $\begin{array}{r}-18 \\
-4 \\
-5 \\
-4\end{array}$ & $\begin{array}{l}154 \\
131 \\
149 \\
126\end{array}$ & $\begin{array}{r}1899 \\
1652 \\
2789 \\
597\end{array}$ & & & & & & \\
\hline $\begin{array}{l}\text { DE } 2 \text { MS } \\
\text { Fritz Peak FP }\end{array}$ & & & & $\begin{array}{l}-6 \\
-2\end{array}$ & $\begin{array}{l}48 \\
24\end{array}$ & $\begin{array}{r}1336 \\
301\end{array}$ & & & \\
\hline $\begin{array}{l}\text { DE } 2 \text { MS } \\
\text { Arecibo FP }\end{array}$ & & & & & & & $\begin{array}{l}4 \\
4\end{array}$ & $\begin{array}{l}46 \\
57\end{array}$ & $\begin{array}{r}916 \\
2764\end{array}$ \\
\hline
\end{tabular}

TABLE 3d. Zonal Wind Differences From HWM90 Between 200 and $350 \mathrm{~km}$ For the Southern Hemisphere

\begin{tabular}{|c|c|c|c|c|c|c|c|c|c|}
\hline \multirow[b]{2}{*}{ Data Set } & \multicolumn{3}{|c|}{$\begin{array}{l}\text { Latitude } \\
60^{\circ} \mathrm{S} \text { to } 90^{\circ} \mathrm{S}\end{array}$} & \multicolumn{3}{|c|}{$\begin{array}{l}\text { Latitude } \\
30^{\circ} \mathrm{S} \text { to } 60^{\circ} \mathrm{S}\end{array}$} & \multicolumn{3}{|c|}{$\begin{array}{l}\text { Latitude } \\
0^{\circ} \text { to } 30^{\circ} \mathrm{S}\end{array}$} \\
\hline & avg & sd & pts & avg & sd & $\overline{p t s}$ & $\overline{\text { avg }}$ & sd & $\overline{\text { pts }}$ \\
\hline $\begin{array}{l}\text { DE } 2 \text { MS } \\
\text { Mawson FP }\end{array}$ & $\begin{array}{l}-13 \\
-28\end{array}$ & $\begin{array}{l}135 \\
113\end{array}$ & $\begin{array}{r}1390 \\
26\end{array}$ & & & & & & \\
\hline $\begin{array}{l}\text { DE } 2 \text { MS } \\
\text { Mt. Torrens }\end{array}$ & & & & $\begin{array}{r}-1 \\
5\end{array}$ & $\begin{array}{l}50 \\
36\end{array}$ & $\begin{array}{r}1388 \\
32\end{array}$ & & & \\
\hline $\begin{array}{l}\text { DE } 2 \text { MS } \\
\text { Arequipa FP }\end{array}$ & & & & & & & $\begin{array}{r}-10 \\
10\end{array}$ & $\begin{array}{l}40 \\
67\end{array}$ & $\begin{array}{r}807 \\
1244\end{array}$ \\
\hline
\end{tabular}

compared in Figure 7. In the northern hemisphere, although agreement between the ground-based radar and optical measurements at Arecibo and the DE 2 and AE-E satellites is generally good, the radar measurements are systematically more northward in the summer early evening. In the southern hemisphere, the ground based optical data from Arequipa and the DE 2 and AE-E satellite data are in fairly good agreement except in the early equinox evening where Arequipa winds are more southward. The HWM 90 is significantly better in fitting the southern winter data.

High-latitude zonal wind data for three seasons are shown in Figure 8. At high latitudes the lack of radar data means the local time coverage is generally poorer than for the meridional component, although data are present for all seasons. In the northern hemisphere, the ground-based optical data (Sondrestrom, Svalbard, and College) are in fair agreement with the DE 2 mass spectrometer data but appear to have a systematically smaller diurnal variation than the satellite data. This difference is reflected in a somewhat smaller diurnal variation in the HWM90 than in the HWM87. In the southern hemisphere there is an indication of the same type of difference between the Mawson optical data and the satellite data. The high northern latitude data for all seasons from different sources are compared separately with the wind models in Figure 9.

Mid-latitude zonal wind data for three seasons are shown in Figure 10. In the northern hemisphere, the Fritz Peak optical and DE 2 satellite mass spectrometer data are in good agreement, and similarly in the south between the Mt. Torrens optical and DE 2 satellite data. The HWM90 diurnal amplitude is slightly smaller than the HWM87 and in better overall agreement with the data. Coverage is inadequate to clearly delineate seasonal differences.

Low-latitude zonal wind data for three seasons are shown in Figure 11. In the northern hemisphere, the Arecibo optical and DE 2 data are in fairly good agreement, as are the Arequipa optical and DE 2 data in the southern hemisphere, although the Arequipa data appear somewhat more eastward in the early evening than the satellite data. In northern summer the older model appears somewhat better than the newer. 


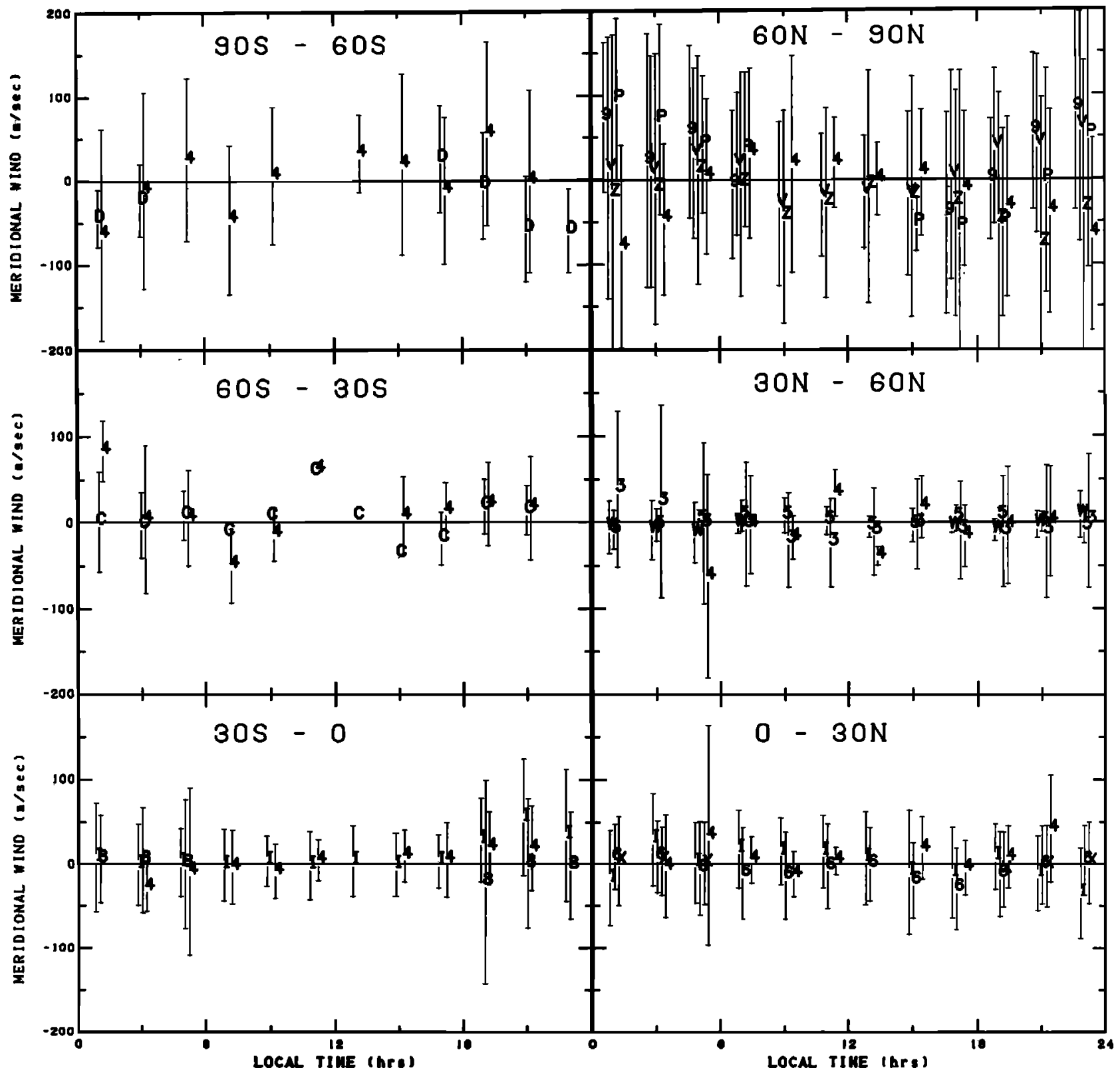

Fig. 2. Difference between measured and HWM90 model meridional winds (positive northward) versus local time for six latitude groupings. Data taken between 200 and $350 \mathrm{~km}$ for Ap<20 were averaged in 2-hour local time bins separated by source. The bars indicate the standard deviation of the data within each altinde bin (when larger than the symbol). The plot symbols indicate data source as follows: C - Mt. Torrens FP; D Mawson FP; I - AE-E MS; J - DE 2 MS; P - Sondrestrom FP; V - Svalbard FP; W - Fritz Peak FP; X Arecibo FP; Z - Sondrestrom IS; 3 - Millstone Hill IS; 4 - DE 2 FP; 5 - St. Santin IS; 6 - Arecibo IS; 8 Arequipa FP; and 9 - College FP. (FP is Fabry-Perot interferometer, MS is mass spectrometer, and IS is incoherent scatter radar.) The data points are offset in local time from the center of the bin for clarity. 


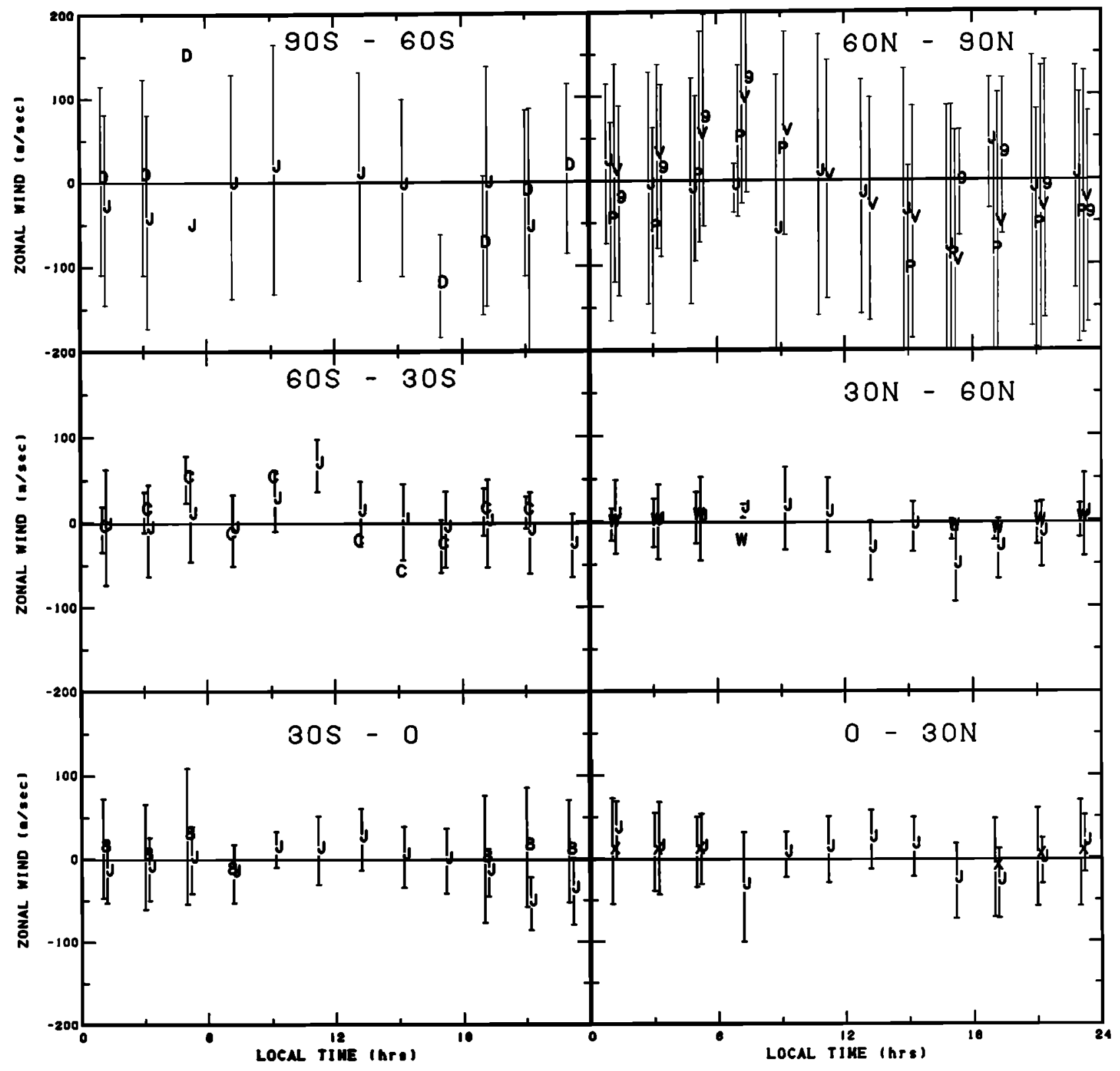

Fig. 3. Same as Figure 2 for zonal winds (positive eastward) between 200 and $350 \mathrm{~km}$. 


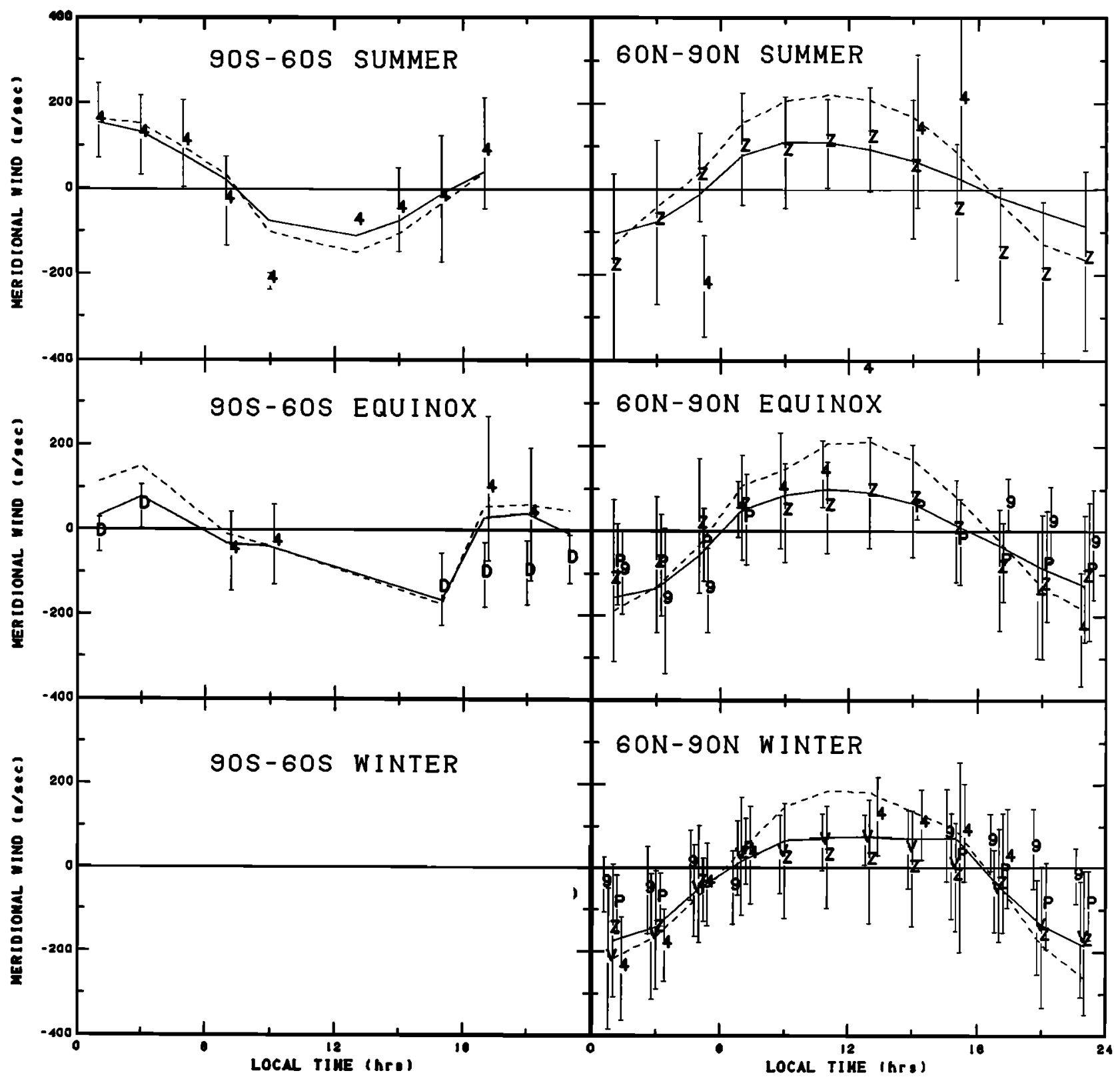

Fig. 4. Measured meridional wind versus local time for three seasons at high latitudes. Data taken between 200 and $350 \mathrm{~km}$ for Ap<20 were averaged in 2-hour local time bins separated by source. The HWM 90 (solid line) and HWM87 (dashed line) winds calculated for each data point and averaged in 2-hour bins are shown for comparison. The plot symbols indicate data source as in Figure 2. 


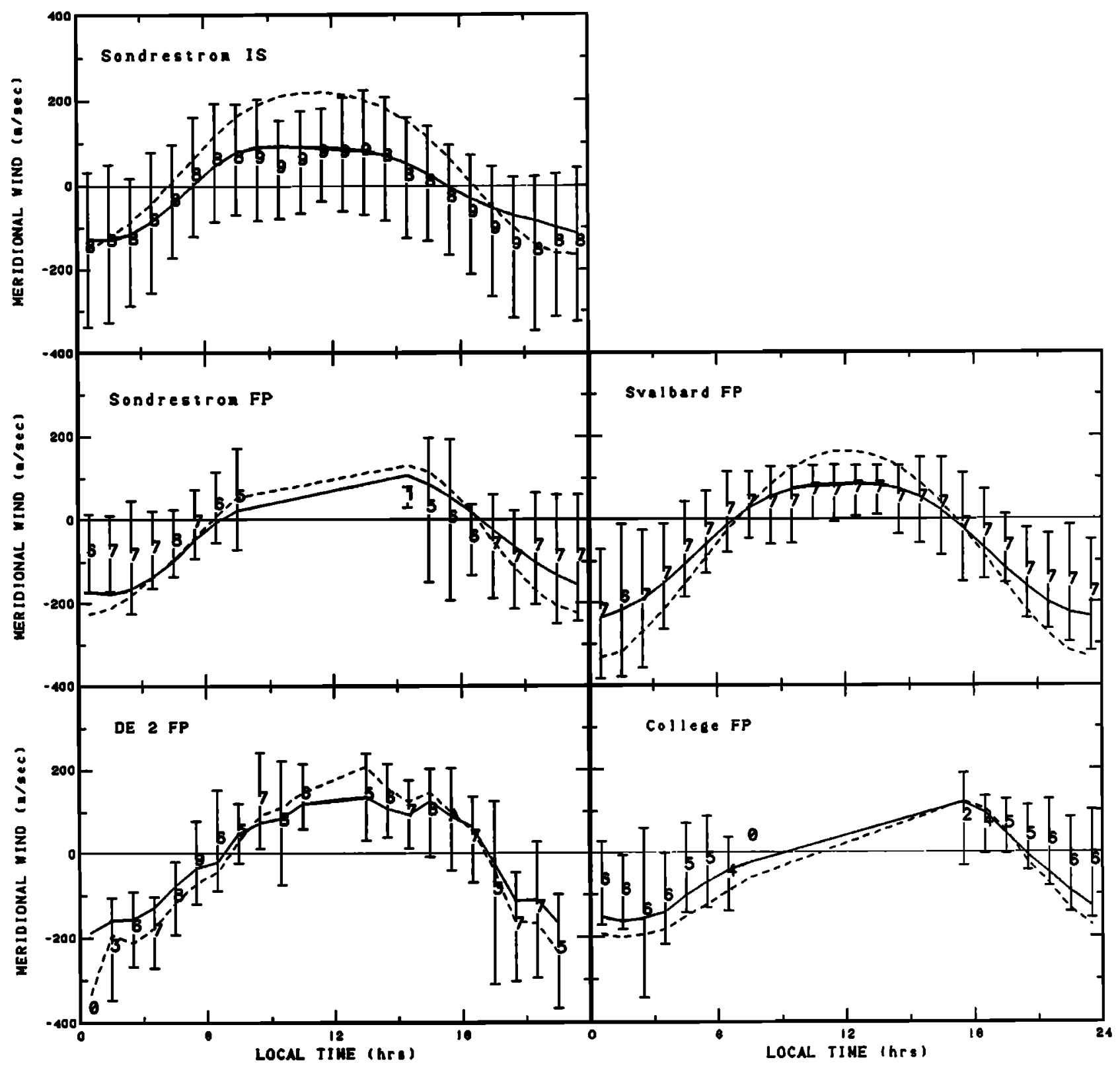

Fig. 5. Measured meridional wind versus local time for high-latitude sites. Data taken between 200 and 350 $\mathrm{km}$ for Ap<20 were averaged in 2-hour local time bins separated by source. The HWM90 (solid line) and HWM87 (dashed line) winds calculated for each data point and averaged in 2-hour bins are shown for comparison. The plot symbols indicate logarithm base 2 of the number of data points in each bin. 


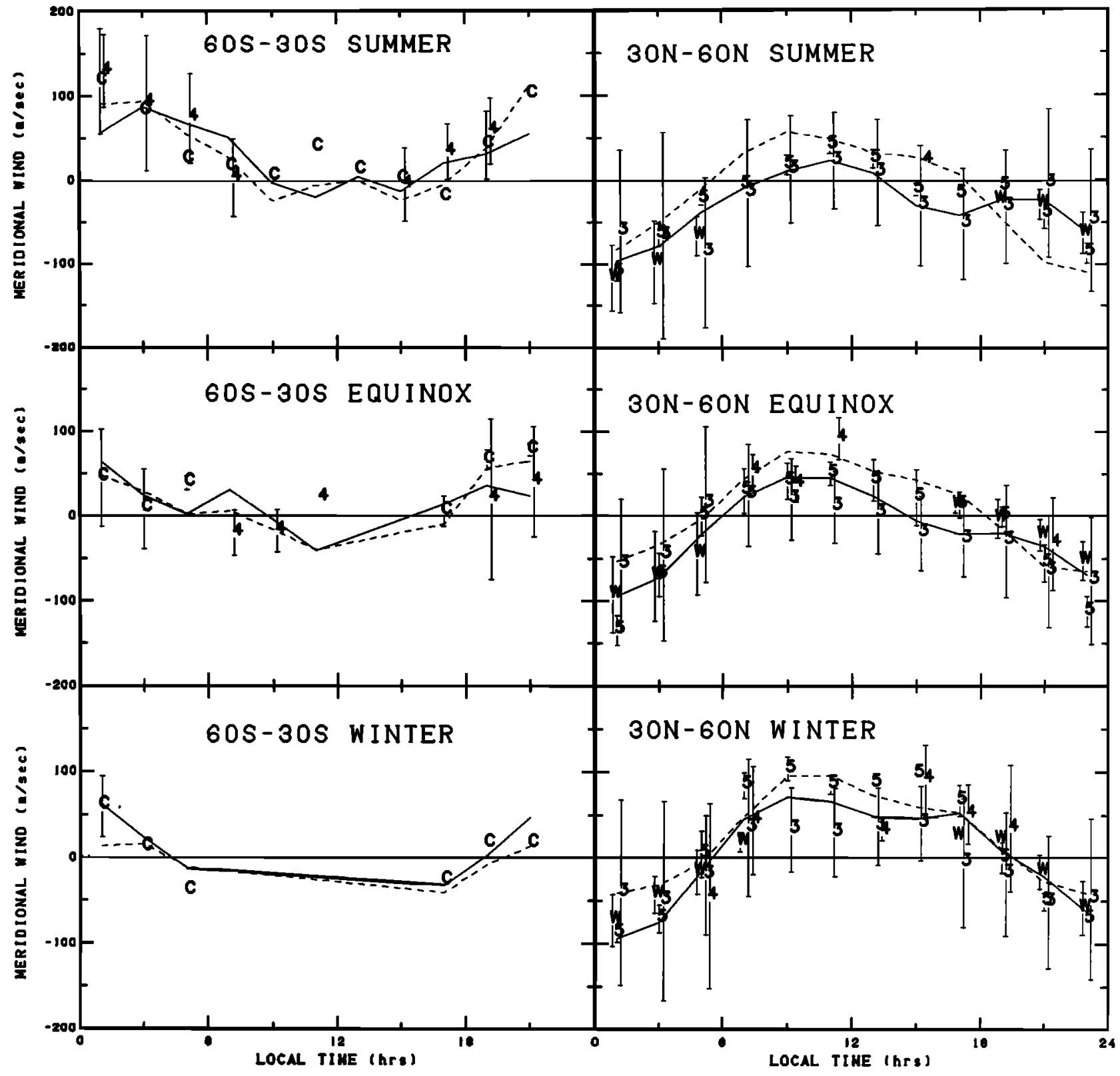

Fig. 6. Same as Figure 4 for mid latitudes. 


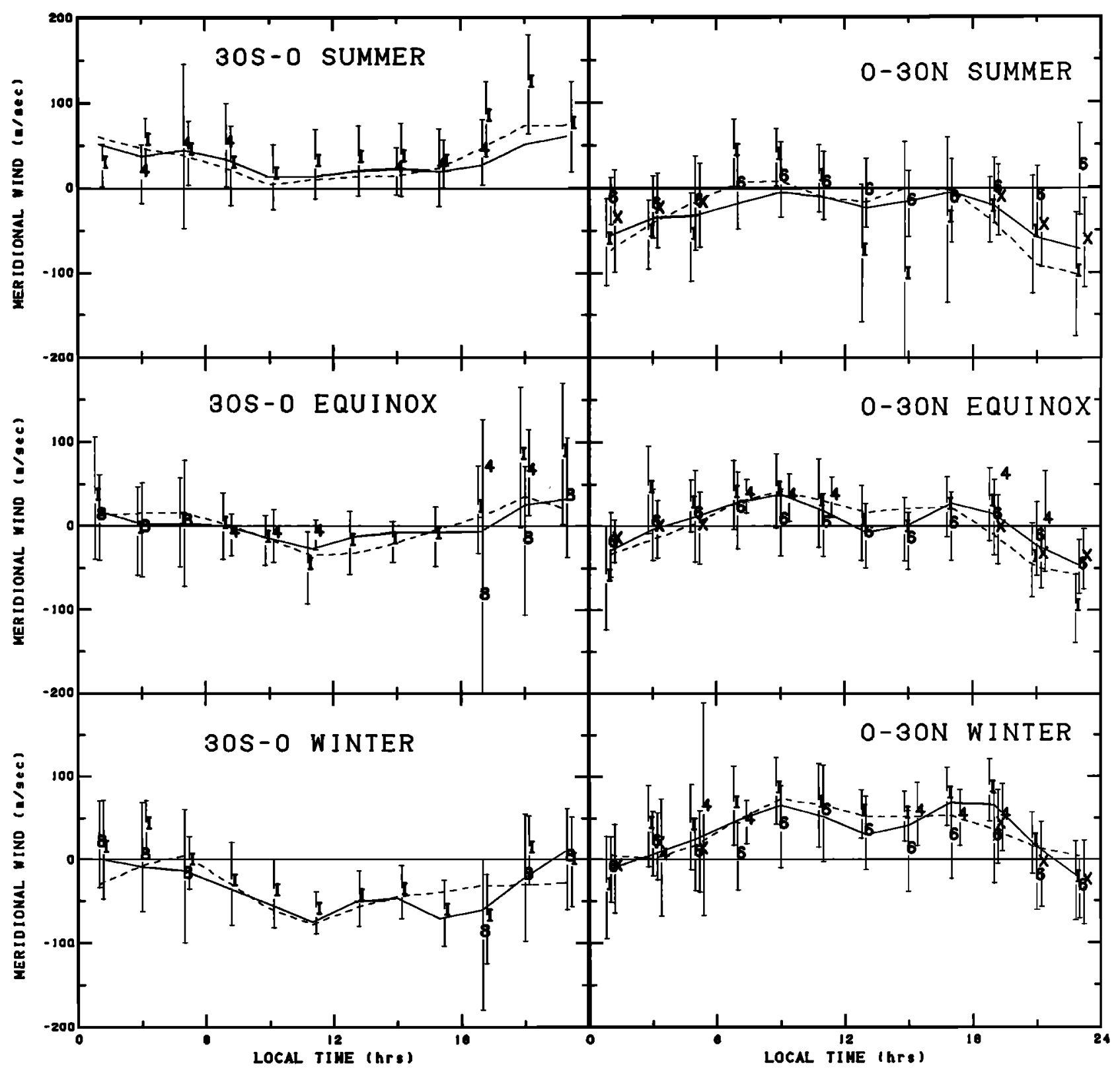

Fig. 7. Same as Figure 4 for low latitudes. 


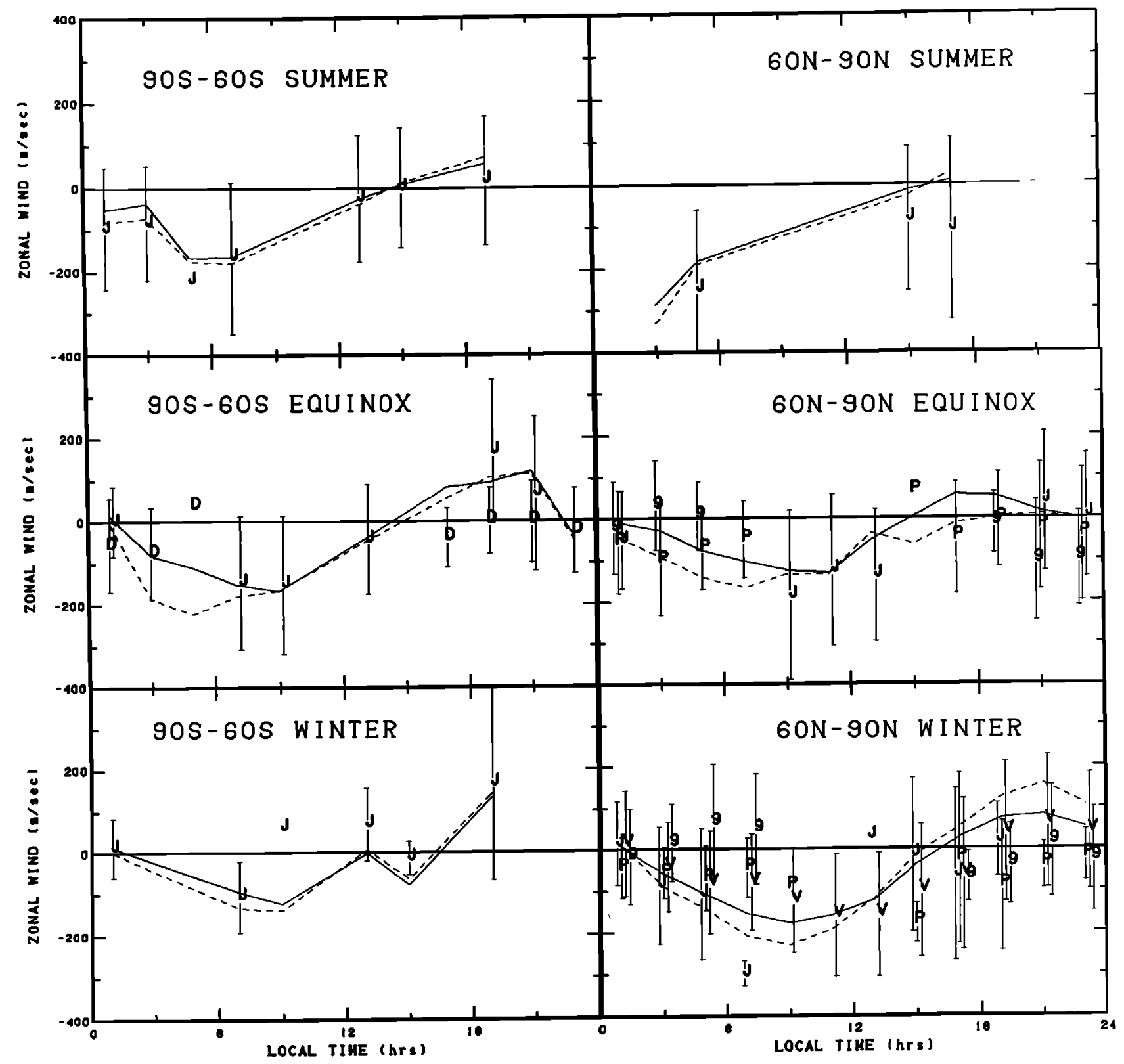

Fig. 8. Measured zonal wind versus local time for three seasons at high latitudes. Data taken between 200 and $350 \mathrm{~km}$ for Ap<20 were averaged in 2-hour local time bins separated by source. The HWM90 (solid line) and HWM87 (dashed line) winds calculated for each data point and averaged in 2-hour bins are shown for comparison. The plot symbols indicate data source as in Figure 2. 


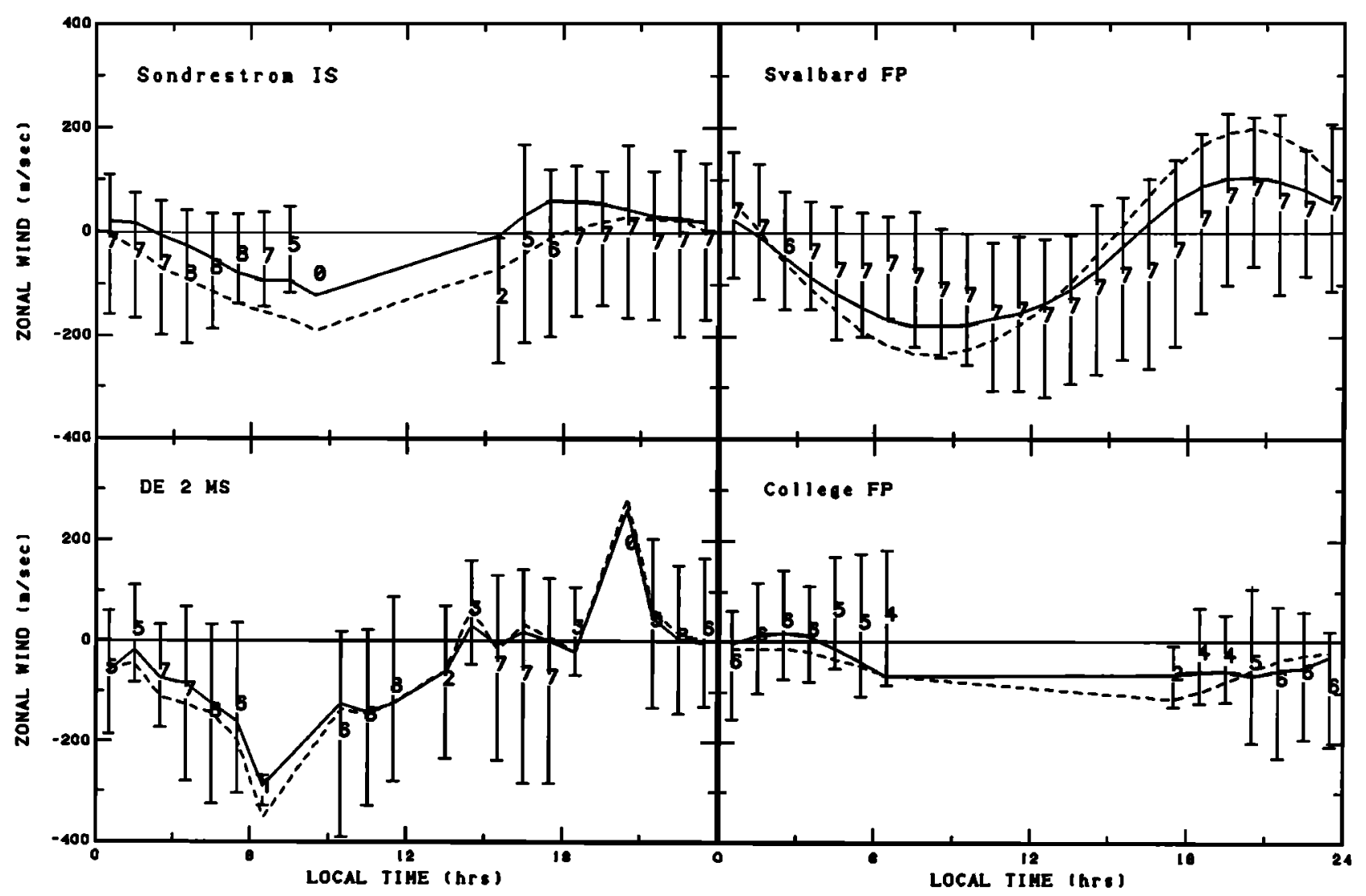

Fig. 9. Same as Figure 5 for zonal winds. 


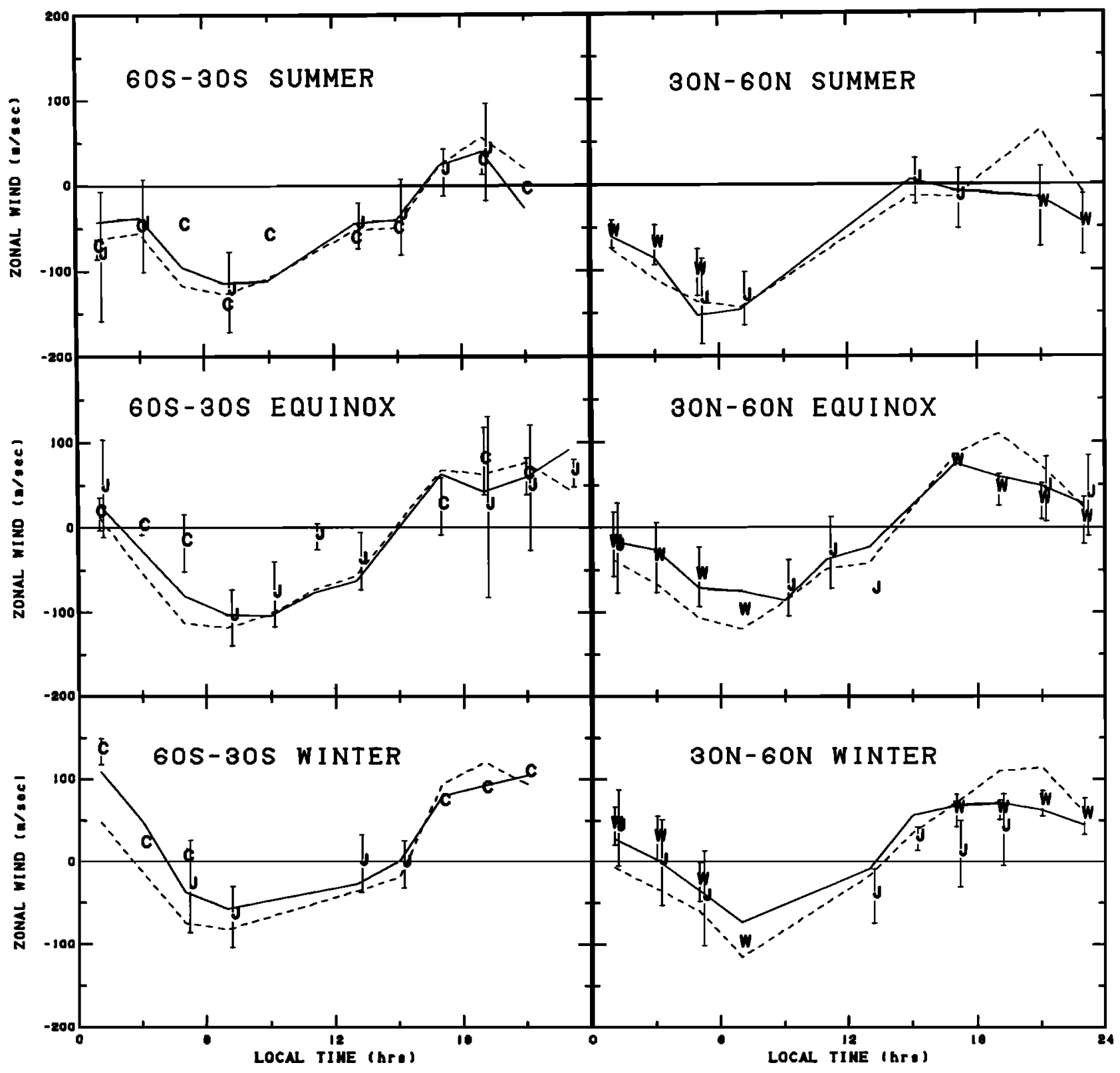

Fig. 10. Same as Figure 8 for mid latitudes. 


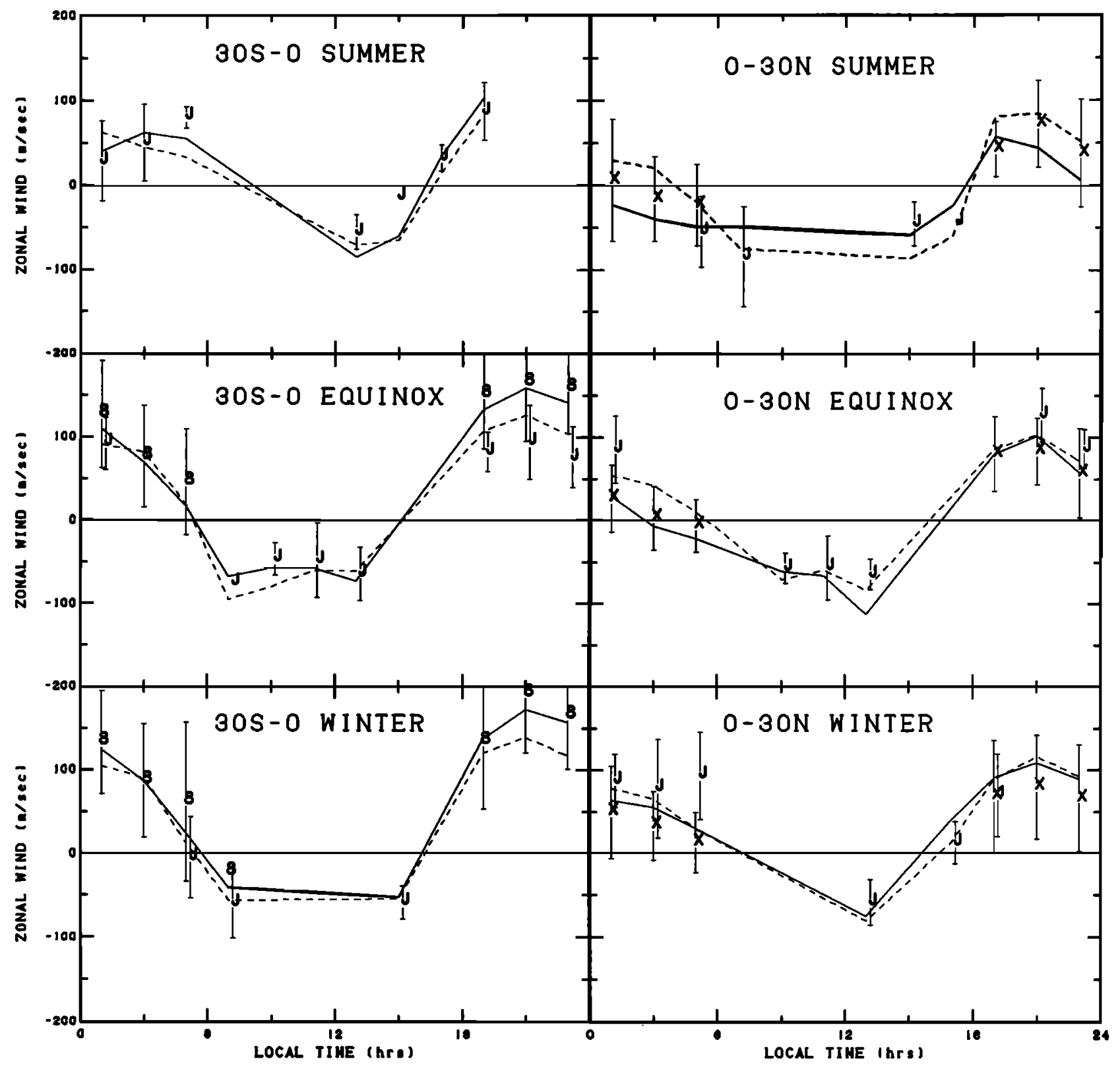

Fig. 11. Same as Figure 8 for low latitudes. 


\subsection{Daily Variations at Low Altitude}

Only the incoherent scatter radar and the AE-E satellite mass spectrometer results cover an extended altitude range including the 130 - to $220-\mathrm{km}$ region. Figure 12 shows local time versus altitude contour maps of binned meridional wind data from the MERWIND tape and the corresponding model predictions. At low latitudes there is insufficient ionization to obtain nighttime data below about $200 \mathrm{~km}$. Nevertheless, the transition to a predominantly semidiumal variation is seen and fairly well captured by the model. The semidiurnal variation becomes obvious only at the lowest altitudes. At both mid and high latitudes in the evening hours there is a marked altitude gradient below $300 \mathrm{~km}$, while the altitude variations are rather small near noon. This evidence for a significant altitude gradient as high as $300 \mathrm{~km}$ complicates the interpretation of ground-based Fabry-Perot measurements, since the point by point altitudes can only be estimated and for simplicity are frequently assumed constant (as in this study). Systematic variations in the altitude of the peak airglow emission have been estimated for Arecibo [Burnside and Tepley, 1989] and College [Sica et al., 1986b], and it would be desirable to include such estimates as a routine part of the resulting wind data bases.

Only the AE-E satellite data near the equator provide any constraint for zonal winds in the 130 - to 220 -km region. For most of the globe, the winds in this altitude range are thus simply extrapolations.

The calculation of meridional winds along the magnetic

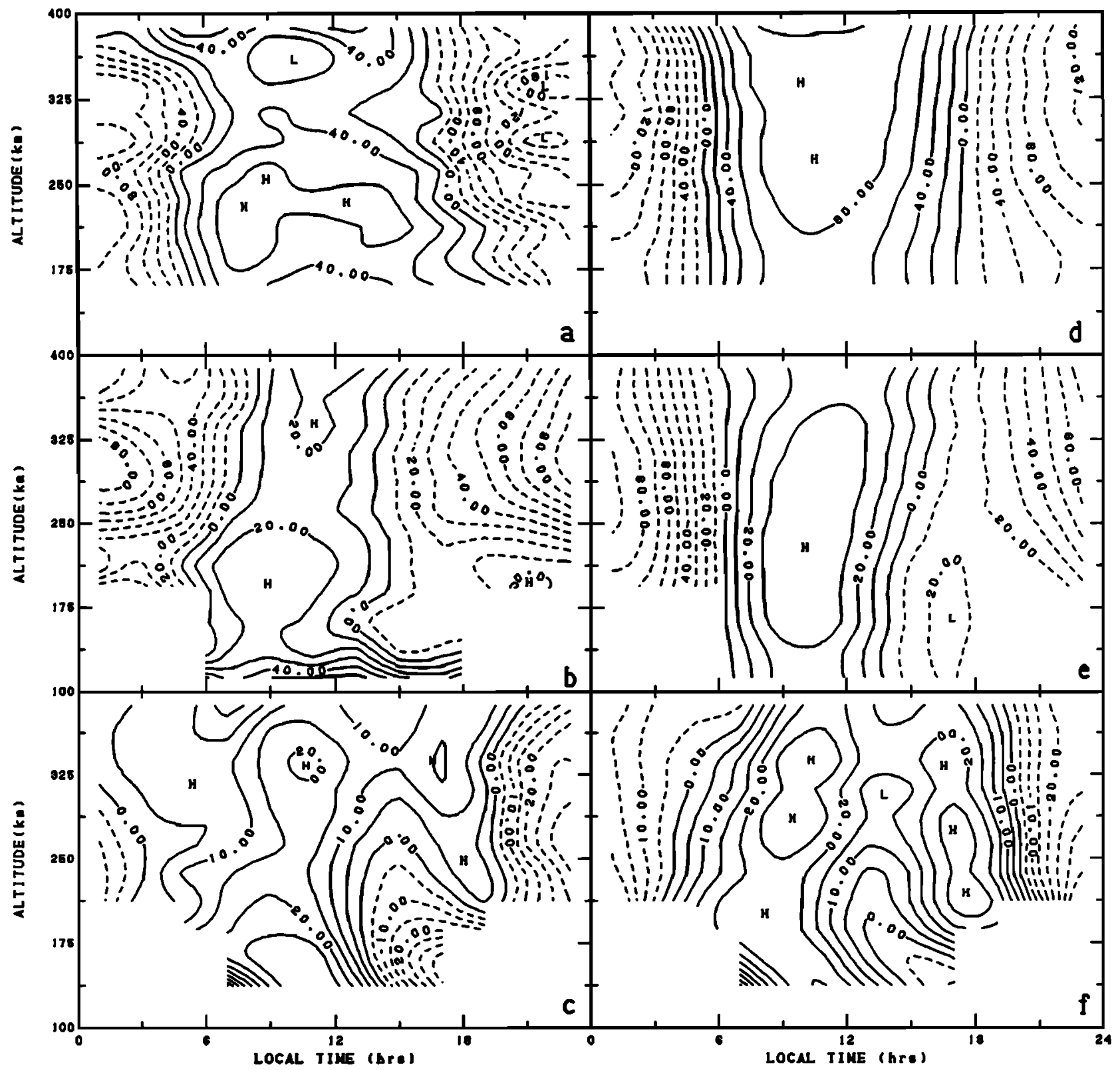

Fig. 12. Contour plots in altitude versus local time of meridional winds (along the magnetic meridian) are shown on the left for (a) Sondrestrom, (b) Millstone Hill, and (c) Arecibo. Corresponding HWM90 model winds are shown on the right $(d, e, f)$. 
meridian from ion drifts at Arecibo and St. Santin obtained for lower thermosphere studies provides another somewhat extended look at the transition between the upper and lower thermosphere as seen in Figure 13. The scale height for phase variations in the semidiumal wind is shorter at Arecibo than at St. Santin and suggests the need for even more altitude resolution to represent the low-latitude phase variations.

Meridional and zonal winds in the $90-$ to $130-\mathrm{km}$ region have been determined at EISCAT, Chatanika, and Millstone Hill by combining $\mathrm{E}$ region ion drift measurements with electric field measurements in the F region. These are compared in Figures 14 and 15 with HWM90. At high latitudes, rapid phase changes are not a problem, but the observed amplitude, particularly of the zonal variation, is underestimated by the model and apparently requires a higher harmonic order in latitude to describe fully. However, there are essentially only data at three latitudes, which are not sufficient to uniquely determine more harmonics. The amplitude of the meridional variation at St. Santin (Figure 13) tends to be a minimum near $120 \mathrm{~km}$, but a maximum at Millstone (Figure 14). Whether this is a systematic longitude difference, sampling problem, or data reduction problem is not clear with the present data sets.

\subsection{Annual Variations at High Altitude}

The annual variation of meridional wind data between 200 and $350 \mathrm{~km}$ for six latitude groups is shown in Figure 16, where the HWM90 model with no annual variation terms has been subtracted from the data in order to emphasize the relatively small diurnally averaged annual variations and then compared to the annual variation terms of the model calculated at the data points. As expected from HWM87, there is little annual variation at high latitudes, but at mid and low latitudes the annual variation in the meridional wind is well defined and in rather good agreement between the various optical and satellite data sets. The most obvious discrepancy is a more southward wind than average in the late fall at both the Arecibo and Millstone Hill radars. The annual variation from the Arecibo Fabry-Perot is slightly smaller than the model but quite different from the radar in the late fall.

The annual variation of zonal wind data between 200 and $350 \mathrm{~km}$ for six latitude groups is shown in Figure 17, where the HWM90 model with no annual variation terms has been subtracted from the data in order to emphasize diumally averaged annual variations and then compared to the annual variation terms of the model calculated at the data points. An annual variation is present in all latitude groups, and there is a fair agreement among the ground-based optical and satellite mass spectrometer data. The Arecibo optical data at a low northern latitude show a significantly smaller amplitude than modeled. Although not yet available for the whole year, the Arequipa data at a low southern latitude appear to be consistent with or have an even larger annual variation than the model.

\subsection{Annual Variations at Low Altitude}

The lower thermosphere Arecibo and St. Santin magnetic meridian data show the transition of the annual variation between the upper and lower thermosphere as seen in Figure 18. There is evidently a reversal from winds flowing away

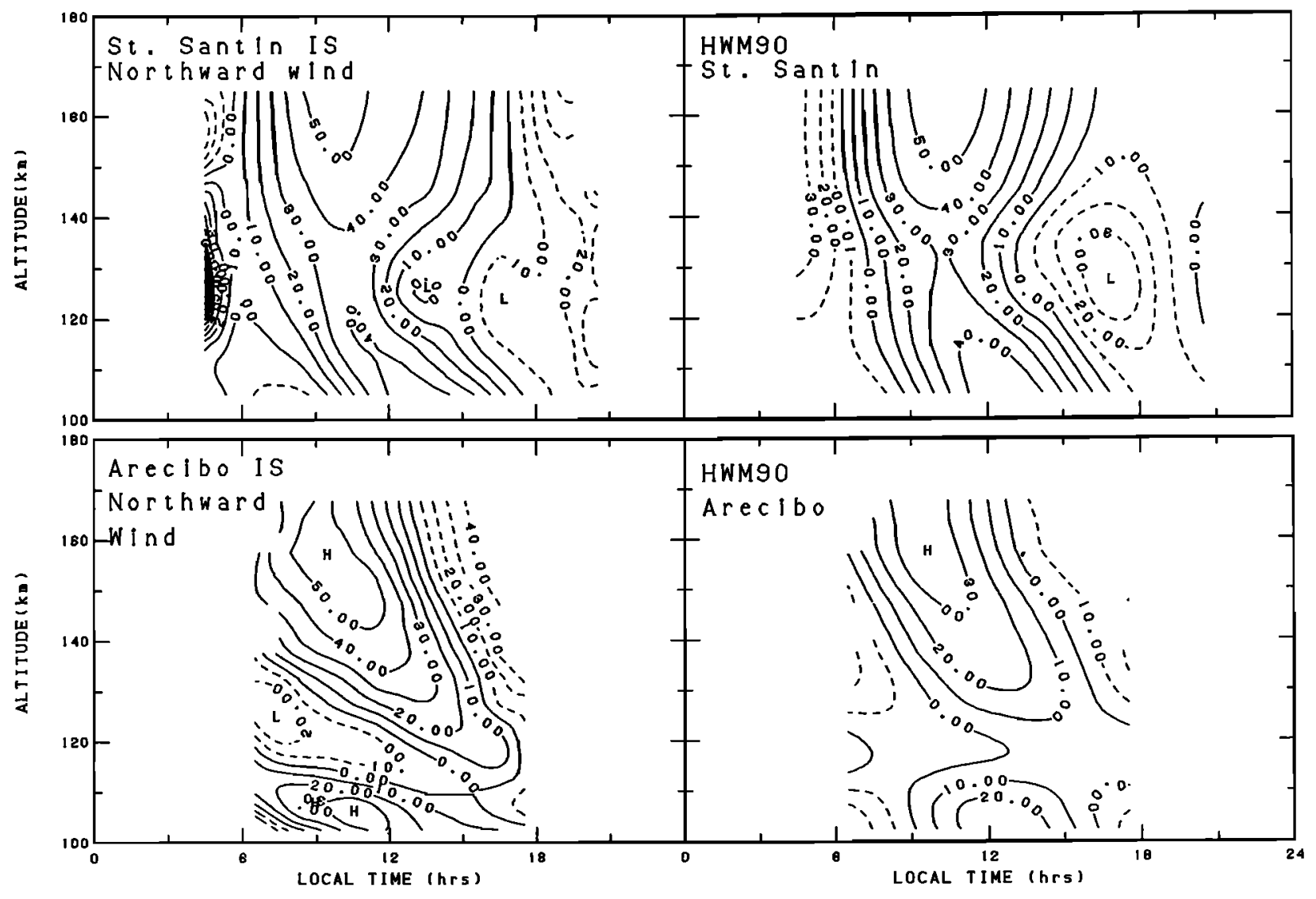

Fig. 13. Contour plots in altitude versus local time of meridional winds (along the magnetic meridian) are shown on the left for St. Santin and Arecibo and corresponding HWM90 winds on the right. 


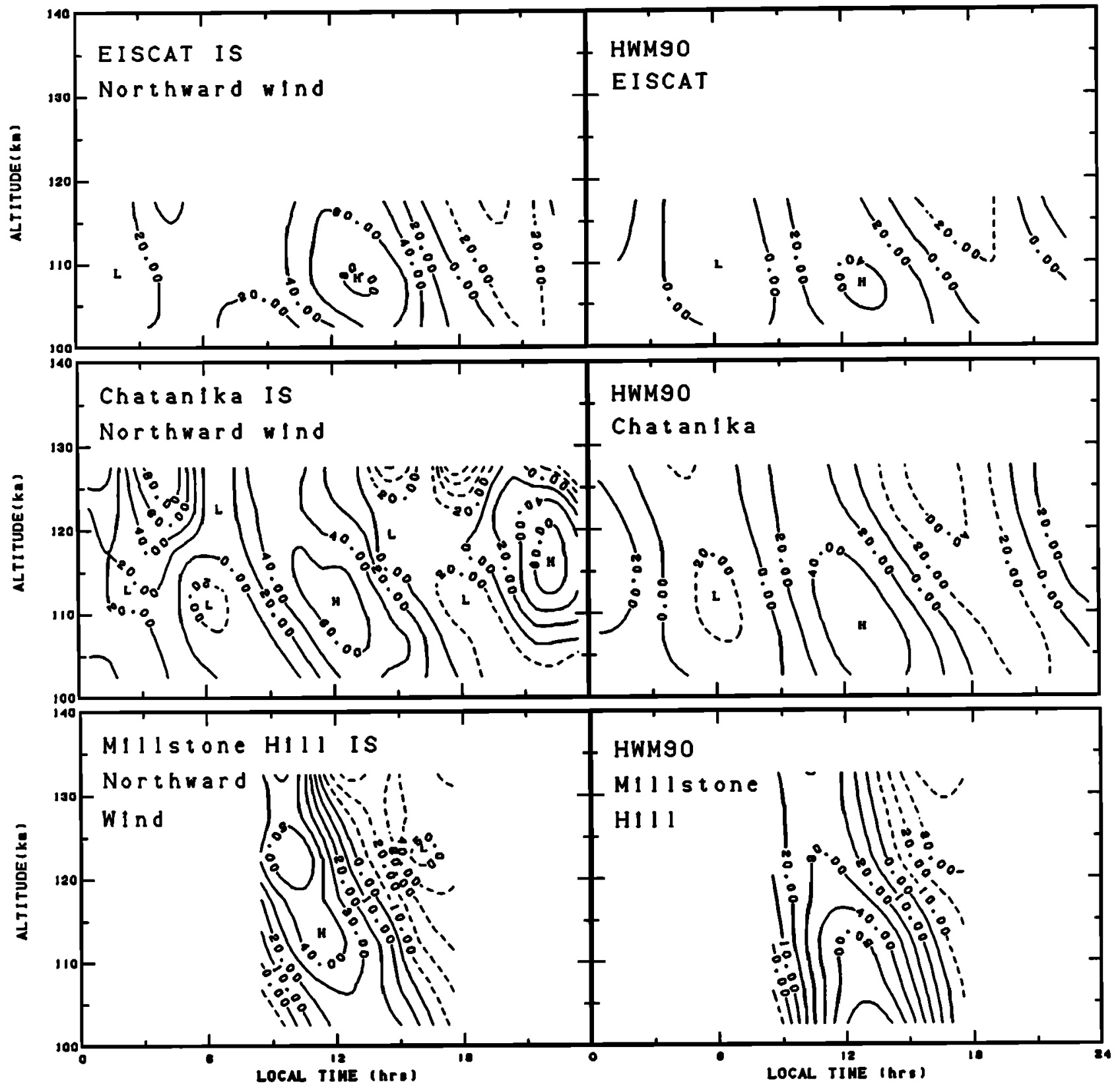

Fig. 14. Same as Figure 13 for EISCAT, Chatanika, and Millstone Hill with corresponding model winds.

from the summer hemisphere to winds flowing toward the summer hemisphere near $140 \mathrm{~km}$, with the model reversal being lower in altitude than indicated by these data. This reverse cell appears to weaken approaching $100 \mathrm{~km}$.

At $100 \mathrm{~km}$ there is an overlap of incoherent scatter data near the lower limit of their altitude range of availability and $\mathrm{MF} / \mathrm{meteor}$ radar data near the upper limit of their altitude range of availability. The annual variation of these data and a Groves [1969] model of older data are compared to the HWM90 model in Figures 19 and 20 for the altitude range 98 to $107 \mathrm{~km}$. The MF radar and Groves model tend to show flow away from the summer hemisphere at low latitudes, while the incoherent scatter data tend to show flow toward the summer hemisphere. This result may be a consequence of being near a transition altitude as suggested above (Figure 18). The zonal winds are more in harmony with each other and show a trend for eastward flow in the summer hemisphere and westward in the winter. The zonal winds also show a small semiannual variation which is not obvious in the upper thermosphere data despite the general prevalence of semiannual variations in temperature and density.

The rather small annual average prevailing meridional wind is away from the equator in the HWM90 model and generally toward the equator in the Groves model near $100 \mathrm{~km}$ (Figure 21). The HWM90 result is more in harmony with the incoherent scatter data, but also in reasonable agreement with the MF radar data. The annual average prevailing zonal wind is eastward at mid latitudes and slightly westward near the equator. This is in general agreement with all the data although the EISCAT and Chatanika data suggest an even stronger zonal flow at high latitudes. 


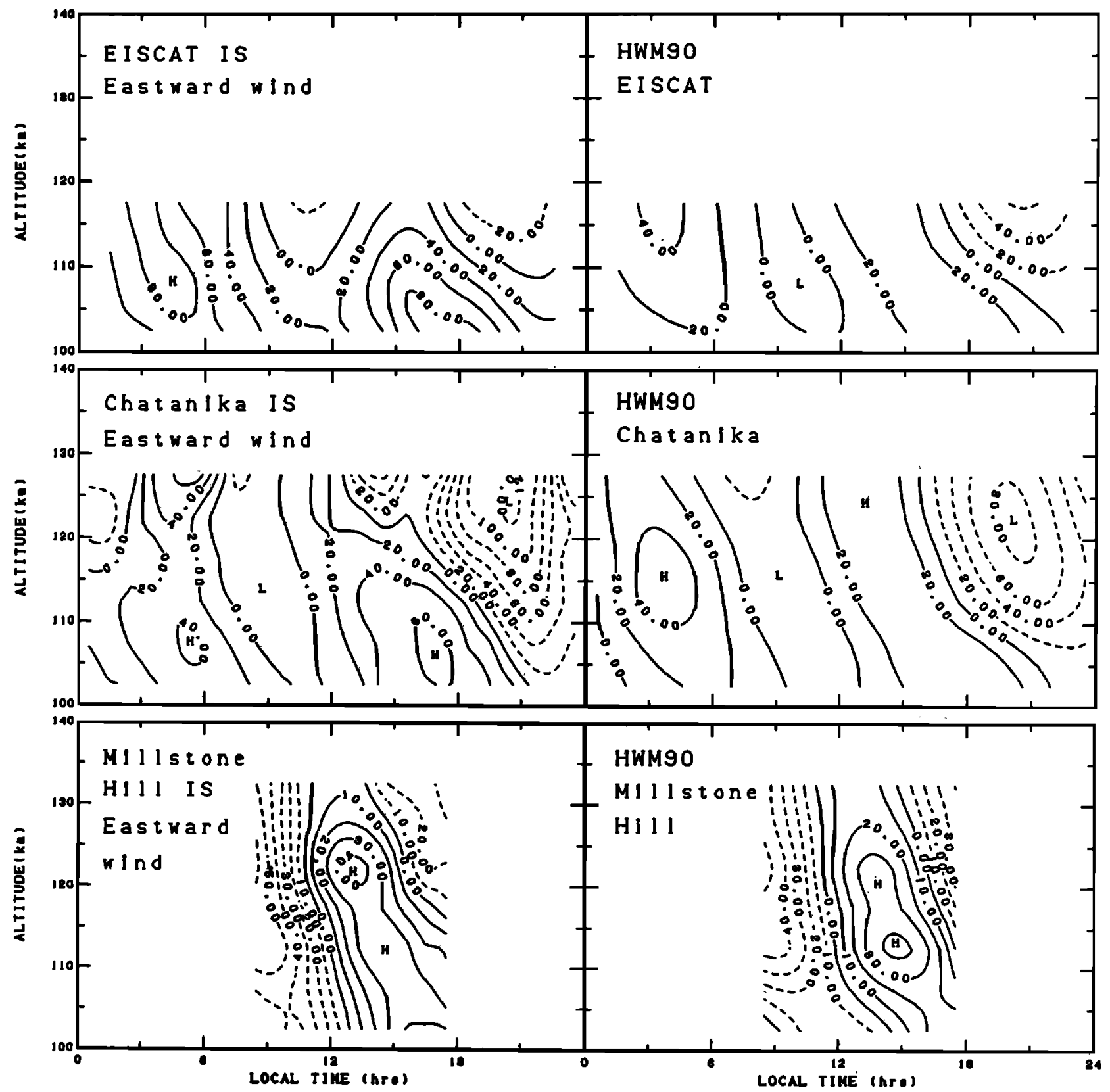

Fig. 15. Same as Figure 13 for zonal winds at EISCAT, Chatanika, and Millstone Hill. 


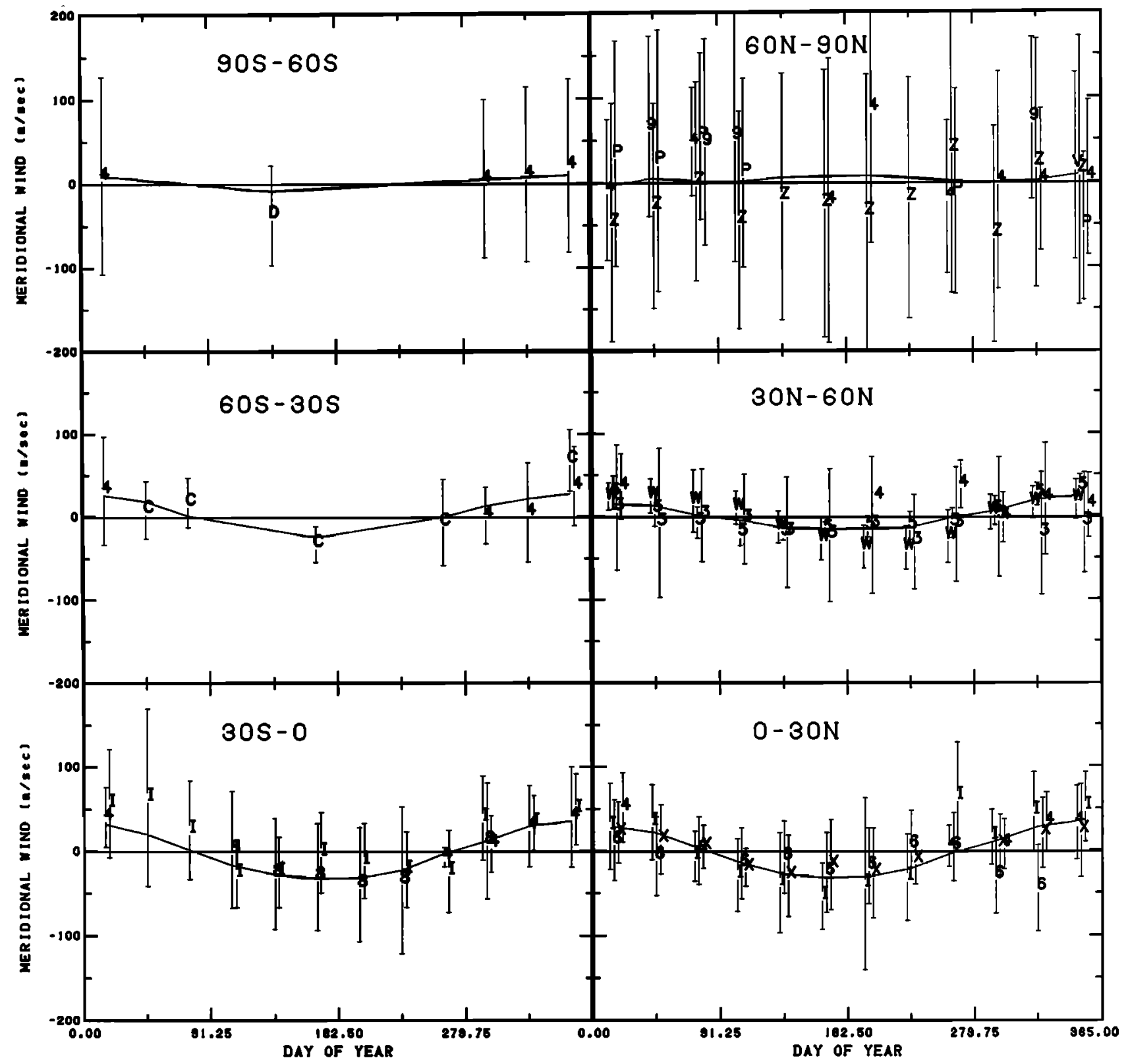

Fig. 16. Measured meridional winds minus HWM90 model winds without annual variation terms versus day of year for six latitude intervals. Data taken between 200 and $350 \mathrm{~km}$ for Ap<20 were averaged in 1 -month time bins separated by source. Corresponding model predictions are connected by the solid line. The plot symbols indicate data source as in Figure 2. 


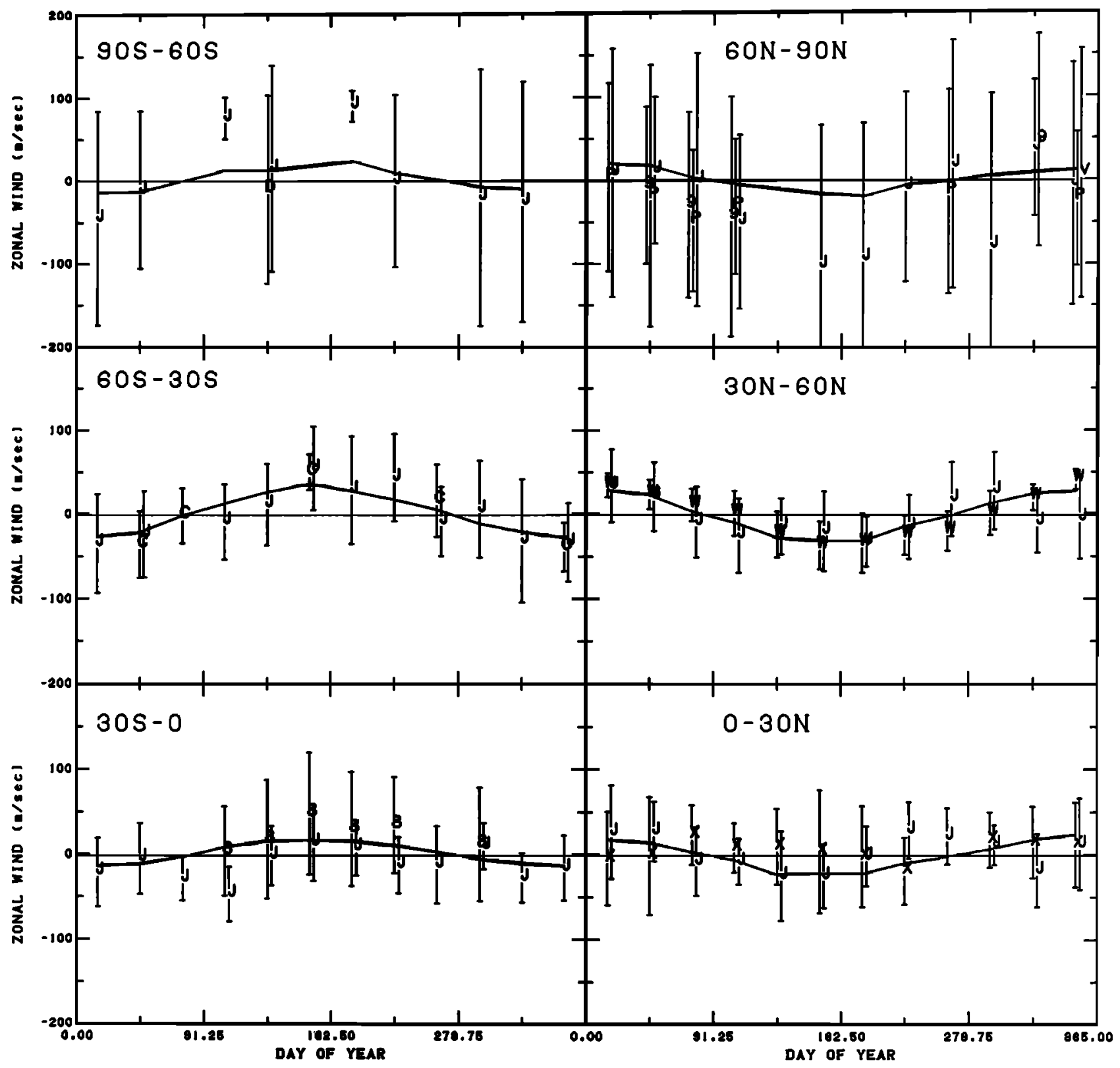

Fig. 17. Same as Figure 16 for zonal winds. 


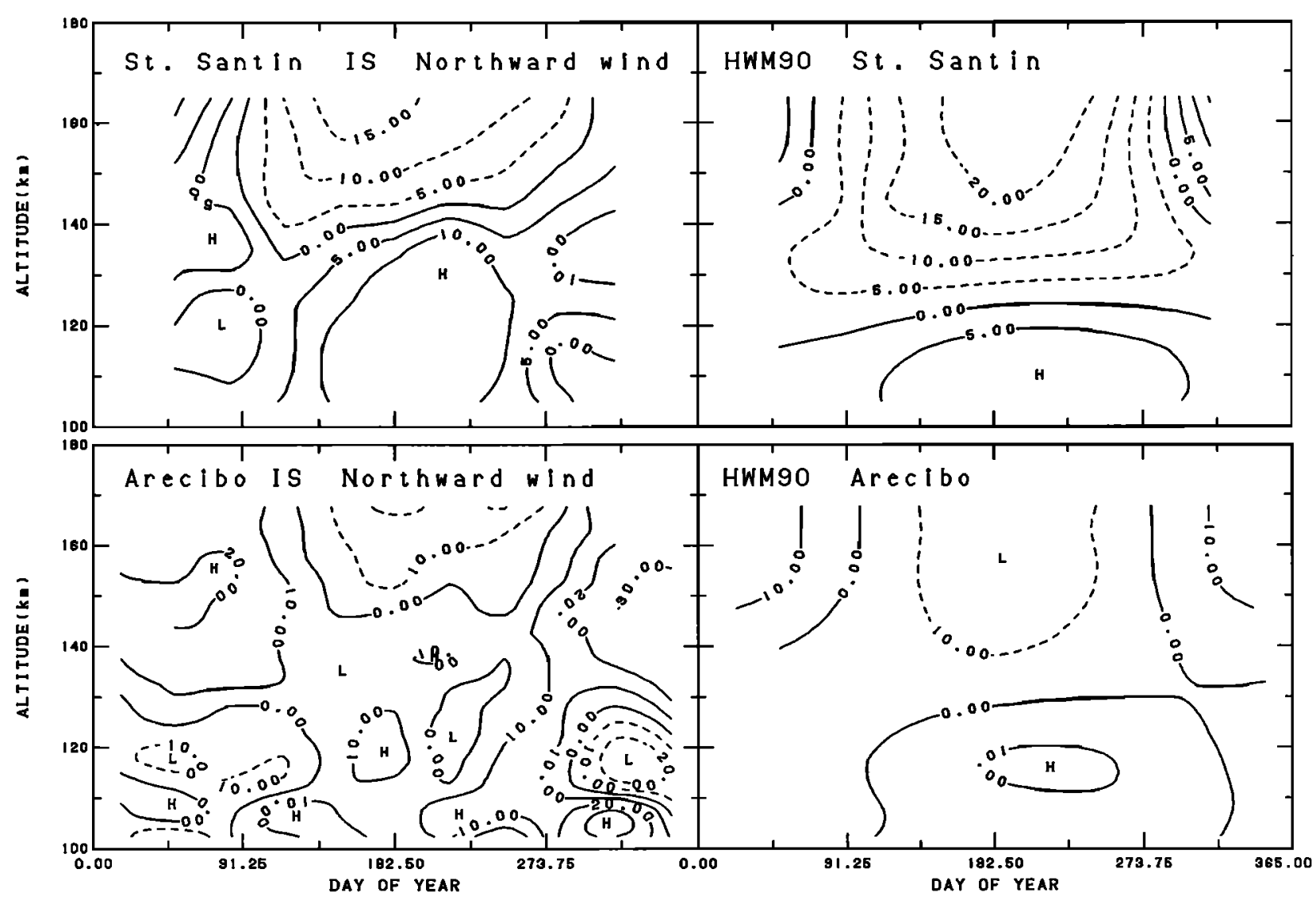

Fig. 18. Contour plots in altitude versus day of year of meridional winds (along the magnetic meridian) are shown on the left for St. Santin and Arecibo and corresponding HWM90 winds on the right.

\subsection{Longitude Variations}

One of the reasons for discrepancies between data sets in Figures 4-10 is longitude/UT variations, which are most prominent at high latitudes. Figure 22 shows data from high northern latitudes which have the HWM90 model subtracted with longitude/UT terms set to zero and then compared to the longitude/UT terms of the model. Satellite data taken in the local evening show a systematic variation around a latitude circle which is fairly consistent with the ground stations and shows that College should have more northward winds than average. The model captures most, but not all, of this variation. The example for zonal winds in the moming hours shows a smaller difference between ground stations than shown by the satellite data and model.

Small systematic longitude variations can be seen in the zonal wind even near the equator. Figure 23 shows longitude variations in the zonal wind at Arecibo and Arequipa. According to model and satellite data, Arecibo should have a more westward wind than average and Arequipa a more eastward wind than average, and this is consistent with the ground-based data.

\subsection{Solar Activity Variations}

One of the goals of this study was the detection and modeling of solar activity effects. Figures 24 and 25 show model predictions of the $250-\mathrm{km}$ meridional and zonal winds versus local time for three solar activity levels and the latitudes for which ground data are available. Compared to the diurnal variation itself, solar activity variations are relatively small and depend on local time and season as well. While the coefficients retained in the model describing the solar activity variations were statistically significant, independent confirmation by obvious trends in individual data sets which cover a wide range of solar activity is either marginal or not possible with the current data. Trends are largely the result of differences between different data sets taken at different parts of the solar cycle. If desired, the solar activity effect in the model can be ignored by maintaining the $10.7-\mathrm{cm}$ solar flux index at a nominal value of 150 .

The variation of meridional wind as a function of solar activity (10.7-cm flux) is shown in Figure 26 for northern mid and high latitudes for two local time divisions. The data have been normalized by the HWM 90 model with the solar activity terms set to zero and then compared to the model predictions for the actual data points. During the daytime at high latitudes, there is positive (northward) trend in both the Sondrestrom radar and optical data with increasing solar activity, but nothing obvious in the Svalbard or satellite data except for the highest solar flux point. At night there is no overall trend, but Svalbard winds may be decreasing (becoming more southward). At mid latitudes, the Millstone Hill radar shows a positive trend in the daytime larger than the average trend, but overall the correlation depends on a few extreme points. A long-term study at Fritz Peak [Hernandez and Roble, 1984] showed that solar cycle effects depended on local time, season, and look direction.

At low latitudes (Figure 27), a small solar activity dependence of the semidiurnal meridional variation is 


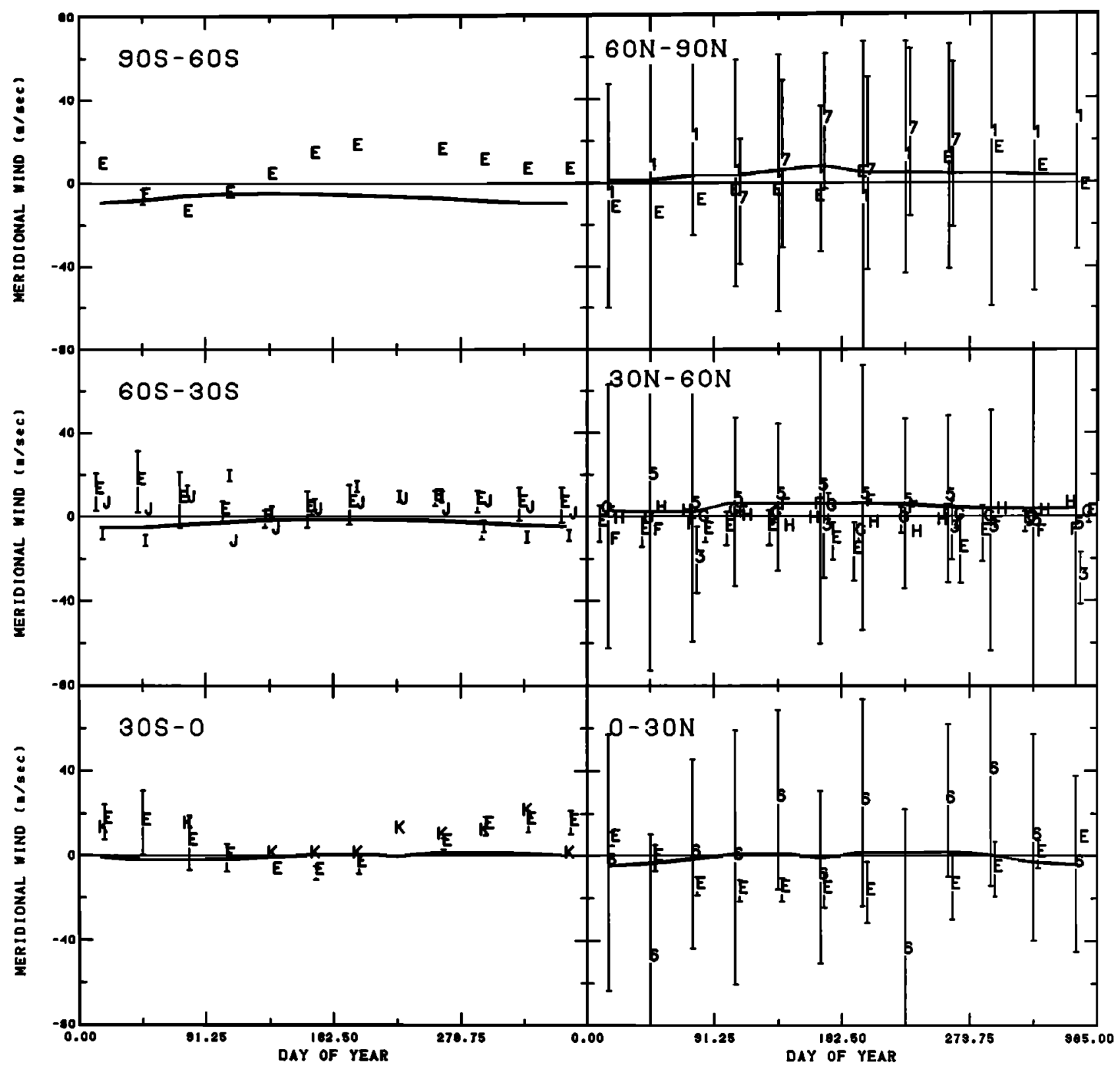

Fig. 19. Measured meridional wind (positive northward) versus day of year for six latitude groups. Data taken between 98 and $107 \mathrm{~km}$ were averaged in 1-month bins separated by source. The HWM90 model without annual and time independent terms was used to normalize the incoherent scatter data to zonal averages. Bars indicate the standard deviation of the data within each bin (when larger than the symbol). The plot symbols indicate data source as follows: E - Groves model; F - Saskatoon; G - Kyoto; H - Atlanta; I Christchurch; J - Adelaide; K - Townsville; 1 - Chatanika IS; 3 - Millstone Hill IS; 5 - St. Santin IS; 6 Arecibo IS; and 7 - EISCAT IS. The data points are offset in day from the center of the bin for clarity. 


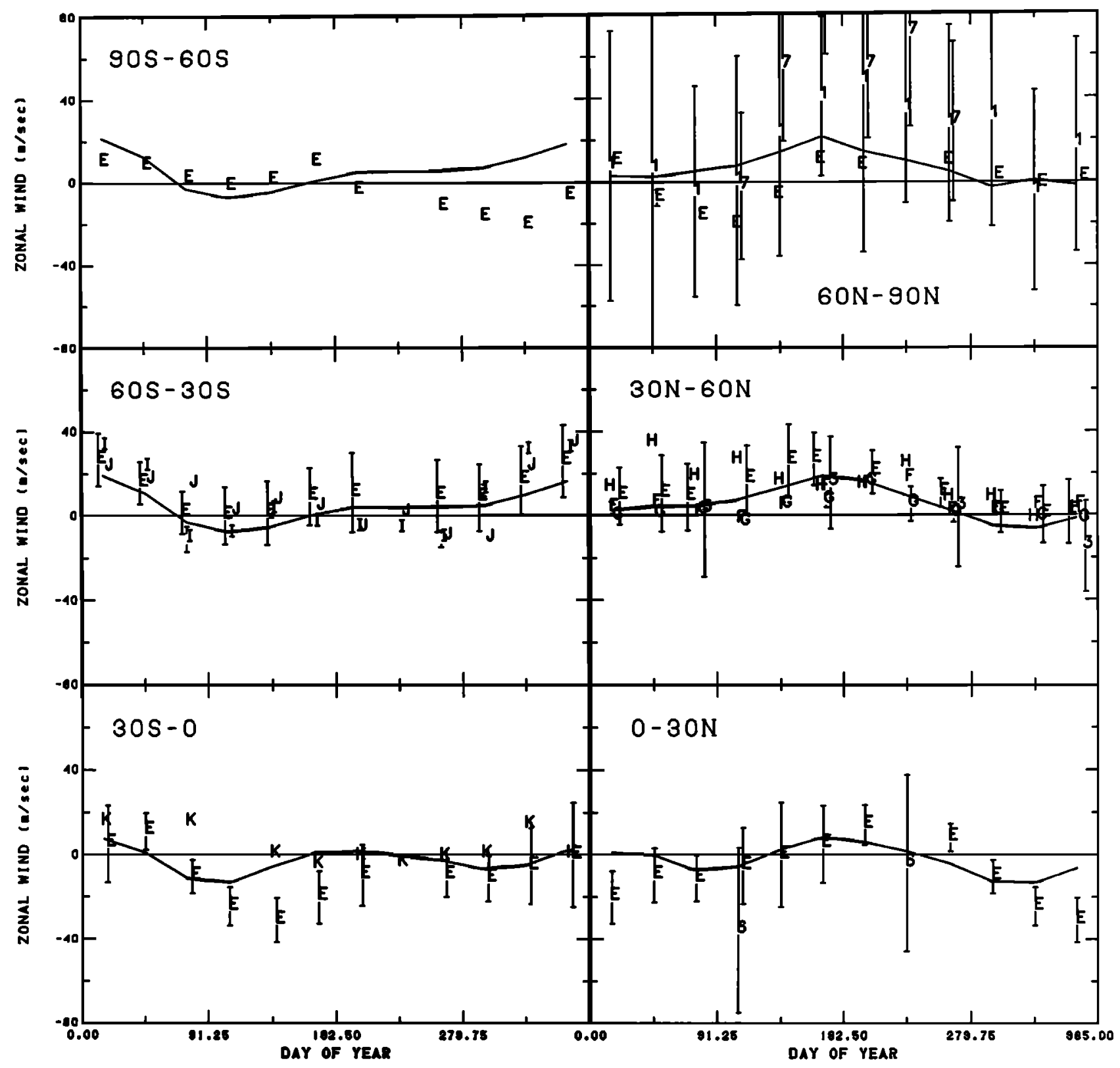

Fig. 20. Same as Figure 19 for zonal winds (positive eastward).

suggested. Here the Arecibo optical data do cover a whole solar cycle and help support the trends, but the magnitude is small. Burnside and Tepley [1989] concluded that the wind field at Arecibo is remarkably unaffected by changes in the solar cycle, and the present analysis is in general agreement with this conclusion.

The variation of zonal wind as a function of solar activity is shown in Figure 28 for the northern hemisphere for two local time divisions. There is fairly clear negative (westward) trend with increasing solar activity at the higher latitudes and positive (eastward) at the lower latitudes. The lack of smoothness in the model curves is a result of rather erratic coverage in terms of altitude, season, etc., at the various solar fluxes.

Complicating the analysis of solar activity variations are systematic correlations in the data. Through accidents of launch date and operations, both the AE-E and DE 2 satellite data have a general correlation between increasing altitude and increasing solar flux. Also, Burnside and Tepley [1989] suggest that the reference altitude for Fabry-Perot observations may change systematically with the solar cycle.

In contrast to the dominance of solar activity variations in thermospheric neutral temperature, density, and pressure, the best that can so far be said for solar activity effects in neutral winds is that they are more likely present at high latitudes than low, but are in any case relatively small compared to other types of variations and probably have a complex dependence on local time, season, altitude, and longitude. The results suggest that changes in coupling of the polar vortex with the neutral atmosphere over the solar cycle (because of changes in electron density), and perhaps seasonally, are more effective in changing the neutral wind than direct changes in solar heating. Changes in the pressure gradient forces over a solar cycle are not simply proportional to the overall temperature and density changes, because of changes in scale height, and when coupled with changes in ion drag apparently lead to only modest changes in wind magnitudes. 


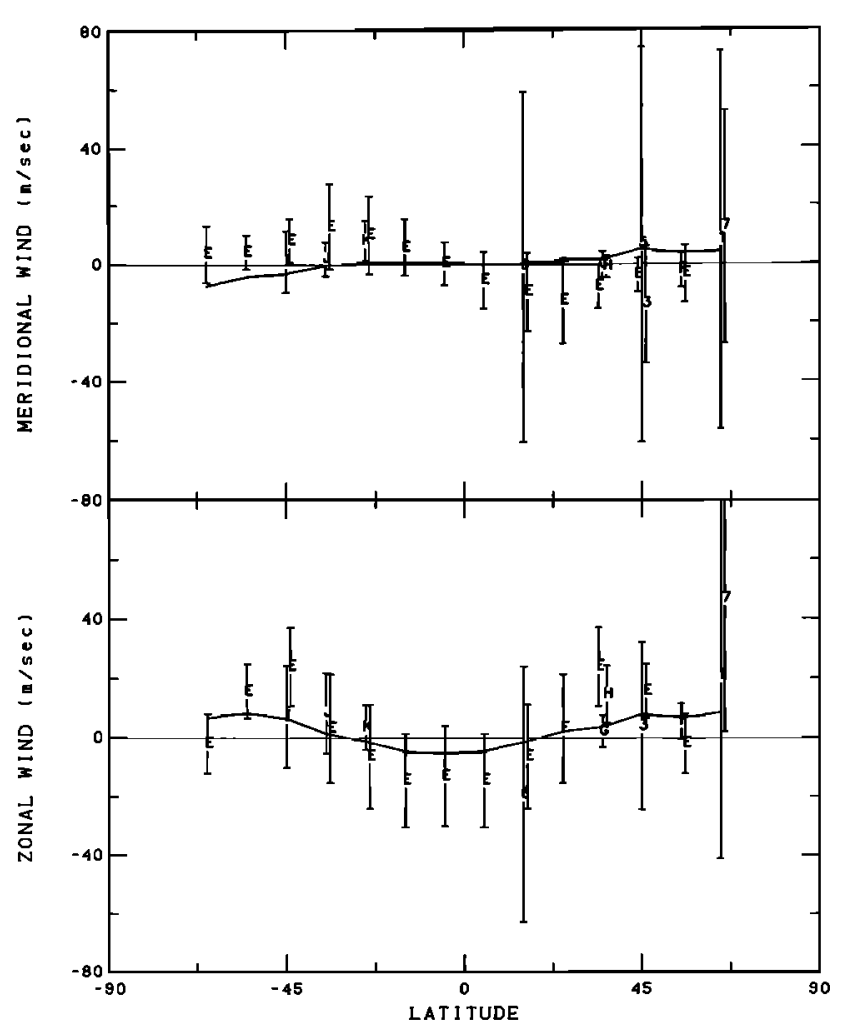

Fig. 21. Measured meridional and zonal winds versus latitude for data taken between 98 and $107 \mathrm{~km}$ and averaged in $10^{\circ}$ bins separated by source. The HWM 90 model without annual and time independent terms was used to normalize the incoherent scatter data to zonal averages. The plot symbols are as in Figure 19.

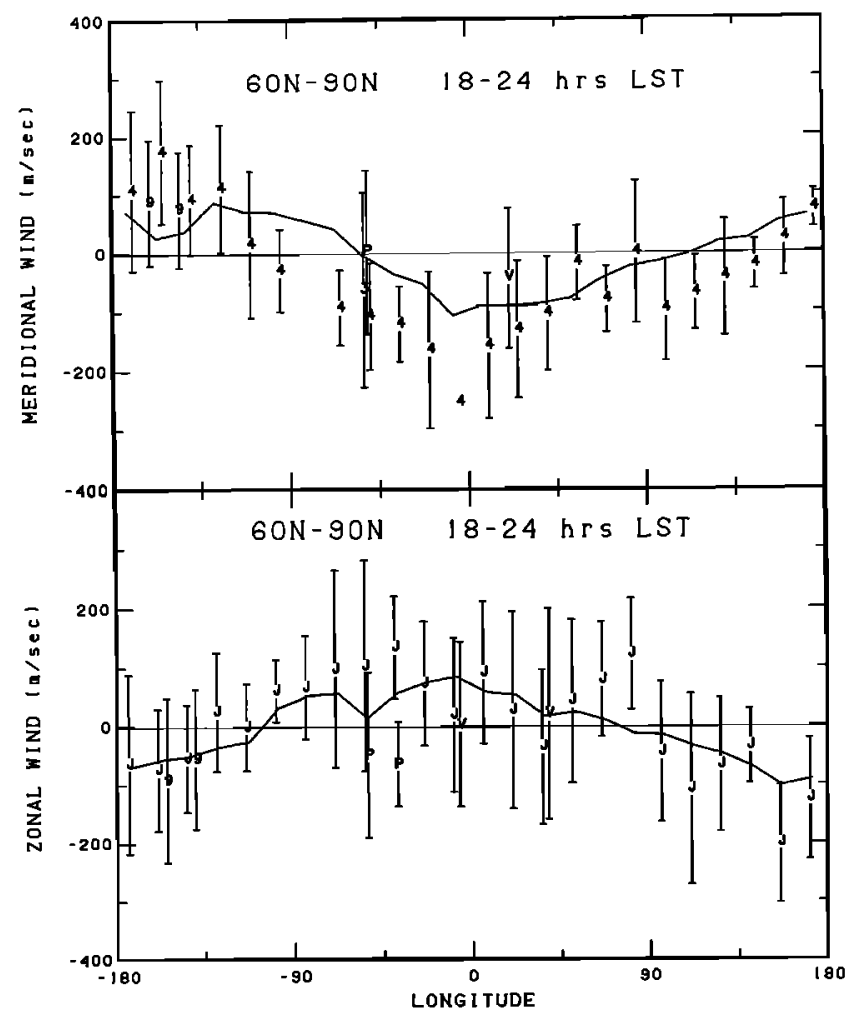

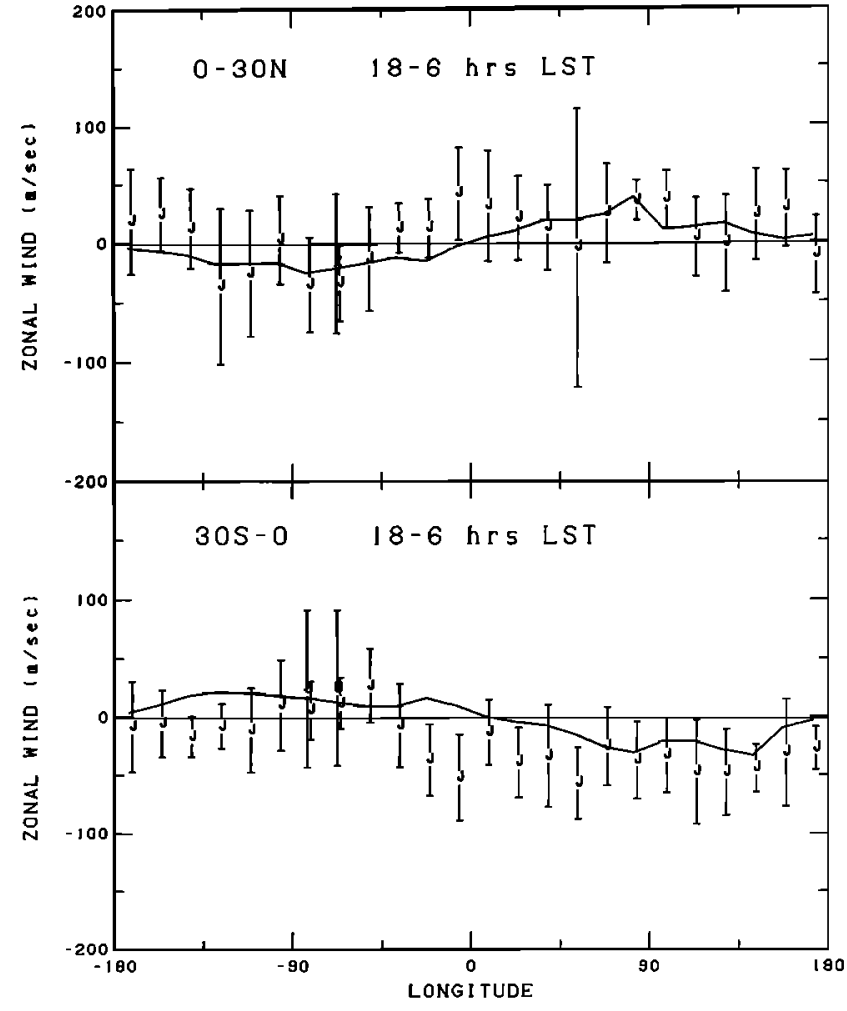

Fig. 23. Measured zonal winds in the $200-$ to $350-\mathrm{km}$ range minus HWM90 model winds without longitude/UT terms averaged in $15^{\circ}$ longitude bins versus longitude for latitudes $0^{\circ}$ to $30^{\circ} \mathrm{N}$ and $30^{\circ} \mathrm{S}$ to $0^{\circ}$ and for 18 to 6 hours local time with corresponding HWM 90 model predictions connected by solid lines. The plot symbols indicate data source as in Figure 2.

Fig. 22. Measured meridional and zonal winds in the 200- to $350-\mathrm{km}$ range minus HWM 90 model winds without longitude/UT terms averaged in $15^{\circ}$ longitude bins versus longitude for $60^{\circ} \mathrm{N}$ to $90^{\circ} \mathrm{N}$ latitude and 18 to 24 hours local time with corresponding HWM90 model predictions connected by solid lines. The plot symbols indicate data source as in Fig. 2. 


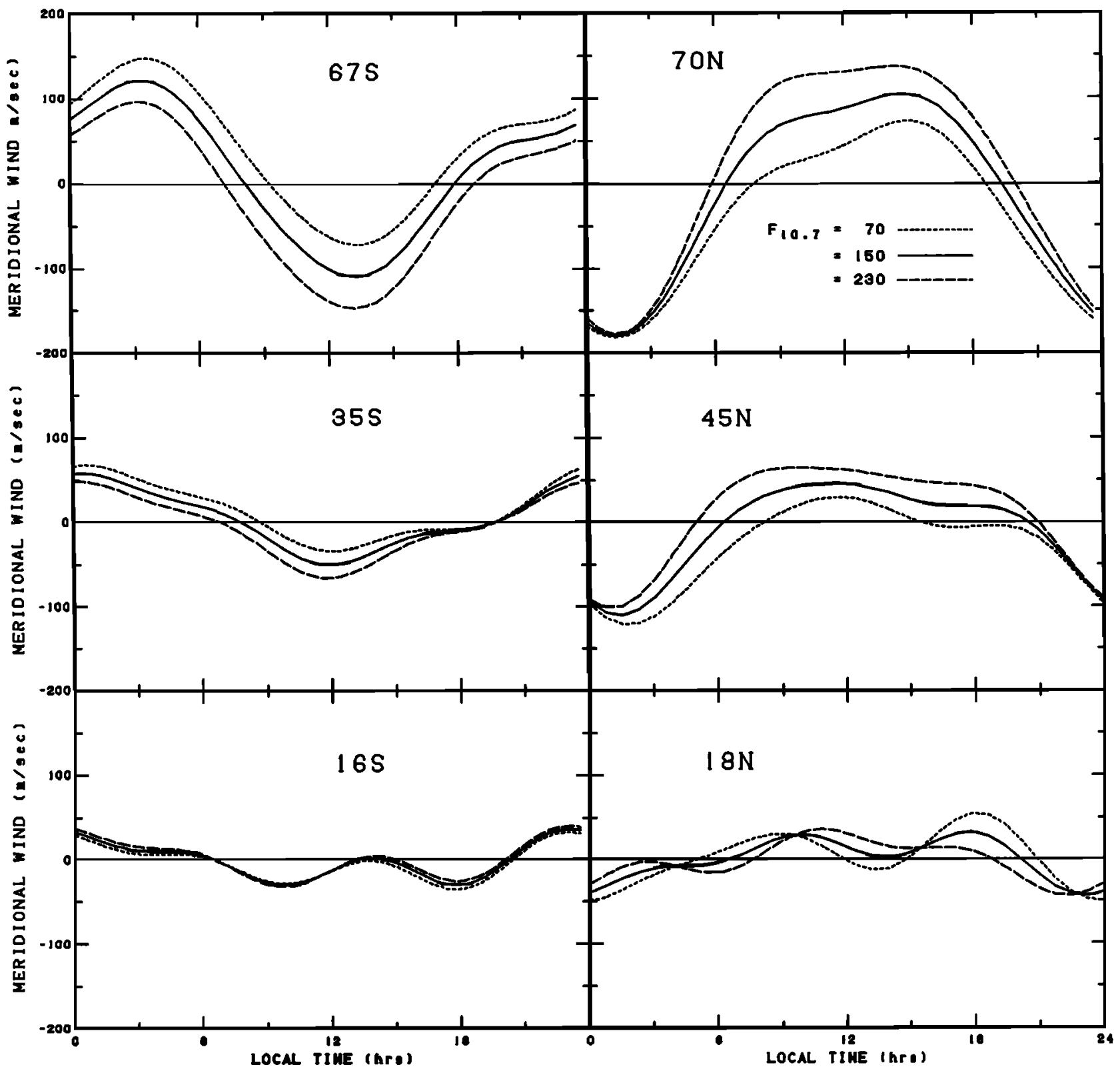

Fig. 24. Zonal and seasonal average HWM90 meridional winds versus local time for six latitudes and three solar activities $(70,150$, and 230 for $10.7 \mathrm{~cm}$ flux).

\section{Summary}

Thermospheric wind data obtained from the Atmosphere Explorer E and Dynamics Explorer 2 satellites have been combined with wind data for the lower and upper thermosphere from ground-based incoherent scatter radar and Fabry-Perot optical interferometers to generate a revision, called HWM90, of the HWM87 empirical model. This revision extends the range of altitude applicability of the model to $100 \mathrm{~km}$.

Comparison of the various data sets with the aid of the model shows in general remarkable agreement, particularly at mid and low latitudes, although there appear to be some systematic differences between radar and optical measurements. The ground-based data allow modeling of seasonal/diurnal variations, which are most distinct at mid latitudes. However, the satellite data aid in comparing the ground-based data in the context of their individual longitudes, latitudes, and altitudes.

While solar activity variations are now included, they are found to be small and not always very clearly delineated by the current data. They are most obvious at the higher latitudes, but appear to have a complex dependence on other variables. The importance of having a long series of data from a given instrument can hardly be overemphasized in the analysis of solar activity variations, but the support of various types of measurements is needed to sort out the complex picture.

The model describes the transition from predominately diurnal variations in the upper thermosphere to semidiumal variations in the lower thermosphere and a transition from summer to winter flow above $140 \mathrm{~km}$ to winter to summer flow below. Significant altitude gradients in the wind are found to extend to $300 \mathrm{~km}$ at some local times and pose complications for interpretation of Fabry-Perot observations. 


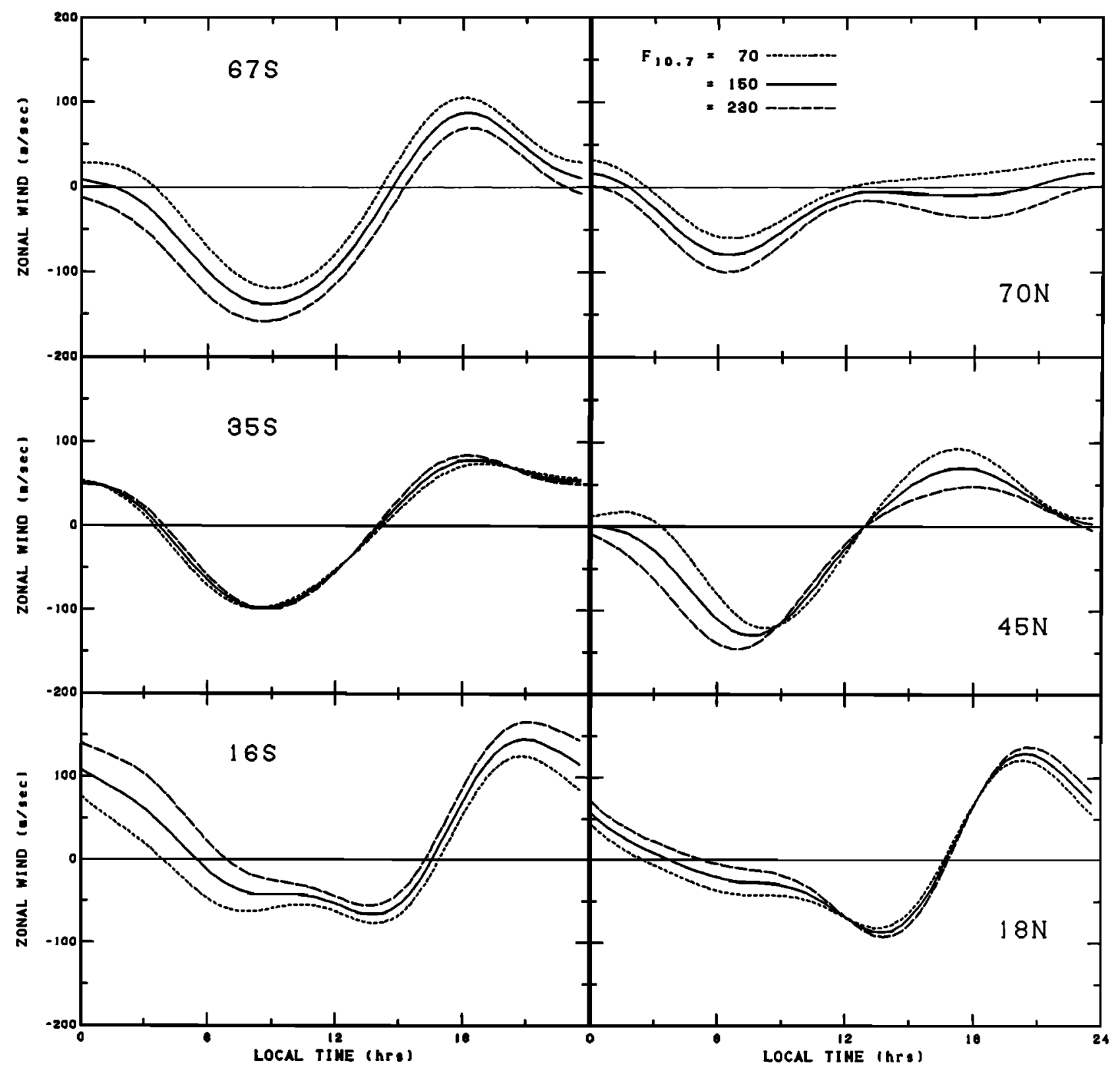

Fig. 25. Zonal and seasonal average HWM90 zonal winds versus local time for six latitudes and three solar activities (70, 150, and 230 for $10.7 \mathrm{~cm}$ flux).

Agreement with $\mathrm{MF} /$ meteor radar at the lower boundary of the present model is encouraging for further modeling efforts in the lower thermosphere.

A FORTRAN subroutine is available from the National Space Science Data Center Request Coordinator Office (NSSDC/code 633.4, Goddard Space Flight Center, Greenbelt, MD 20771; Tel. (301)286-6695; Span NCF::REQUEST).

Acknowledgments. This study made use of the NCAR CEDAR Data Base (formerly NCAR Incoherent-Scatter Radar Data Base), which, along with the Arecibo, Millstone Hill, and Chatanika/Sondrestromfjord radars, and Arequipa Fabry-Perot, is supported by the National Science Foundation. The extension of the CNET (Centre National d'Etudes des Telecommunications) incoherent scatter facility at St.-Santin to a quadristatic configuration was supported by the Institut d'Astronomie et de Geophysique and by the Direction des
Recherches et Moyens d'Essais. The facility is operated with financial support from the Centre National de la Recherche Scientifique. The investigations at College were partially supported by AFOSR-89-0316. The authors wish to thank the Director and staff of EISCAT for their work in providing the data. The EISCAT scientific association is funded by the research councils of Finland, France, Germany, Norway, Sweden, and UK. This work was supported in the UK under grant SD/D/04299 from the Science and Engineering Research Council to Ulster Polytechnic (now the University of Ulster), and also in the USA by grant ATM86-02956 from the National Science Foundation to the University of Alasak, Fairbanks. The authors wish to thank C. A. Tepley for his work in collecting Arecibo Fabry-Perot data and his assistance in making it available.

The Editor thanks P. G. Richards and another referee for their assistance in evaluating this paper. 


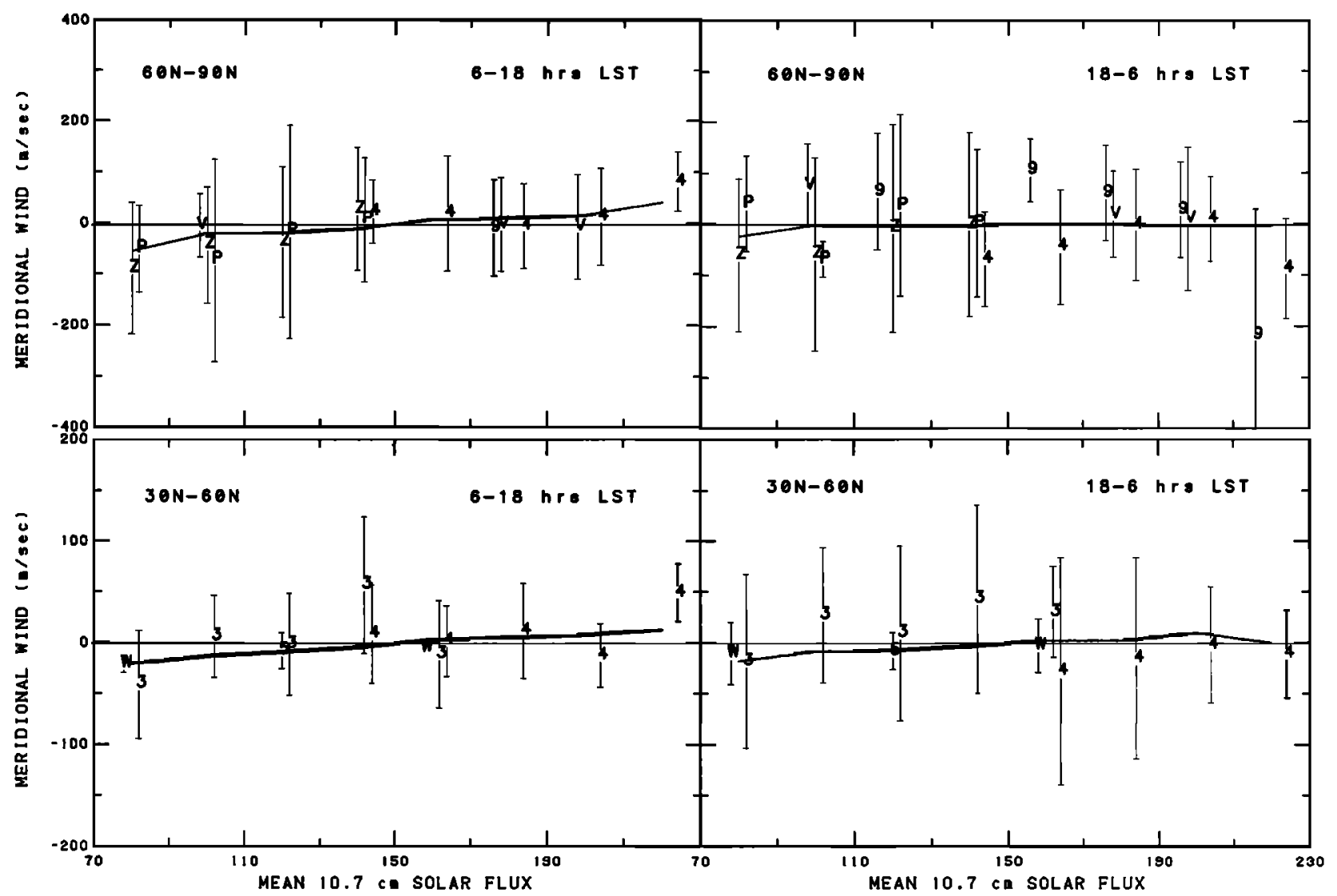

Fig. 26. Measured meridional winds minus HWM90 model winds without solar activity terms averaged in 20 unit bins versus $10.7-\mathrm{cm}$ flux index for data taken between 200 and $350 \mathrm{~km}$ at northern mid and high latitudes with corresponding HWM90 model predictions connected by solid lines. The plot symbols indicate data source as in Figure 2.

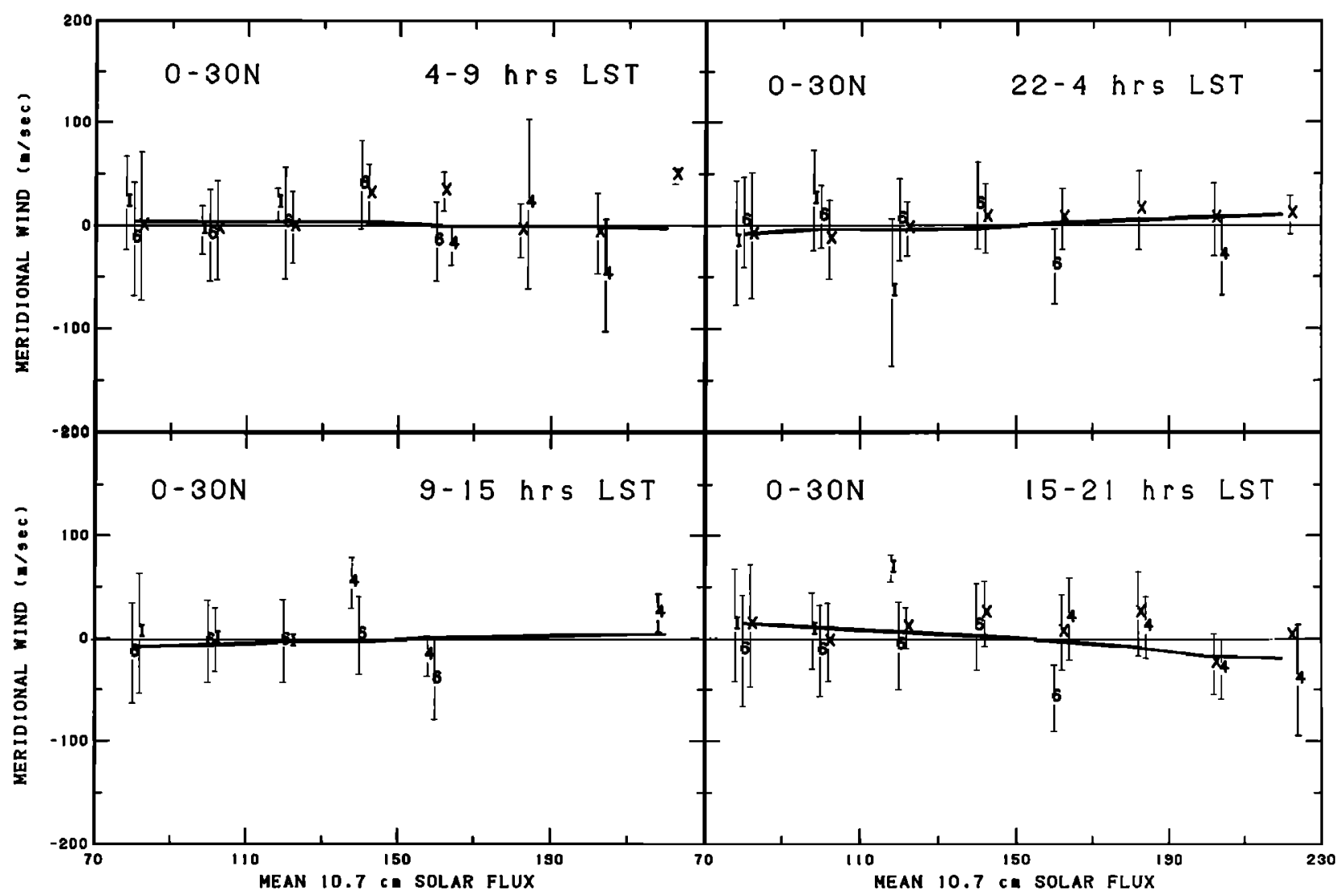

Fig. 27. Same as Figure 26 for low latitudes. 


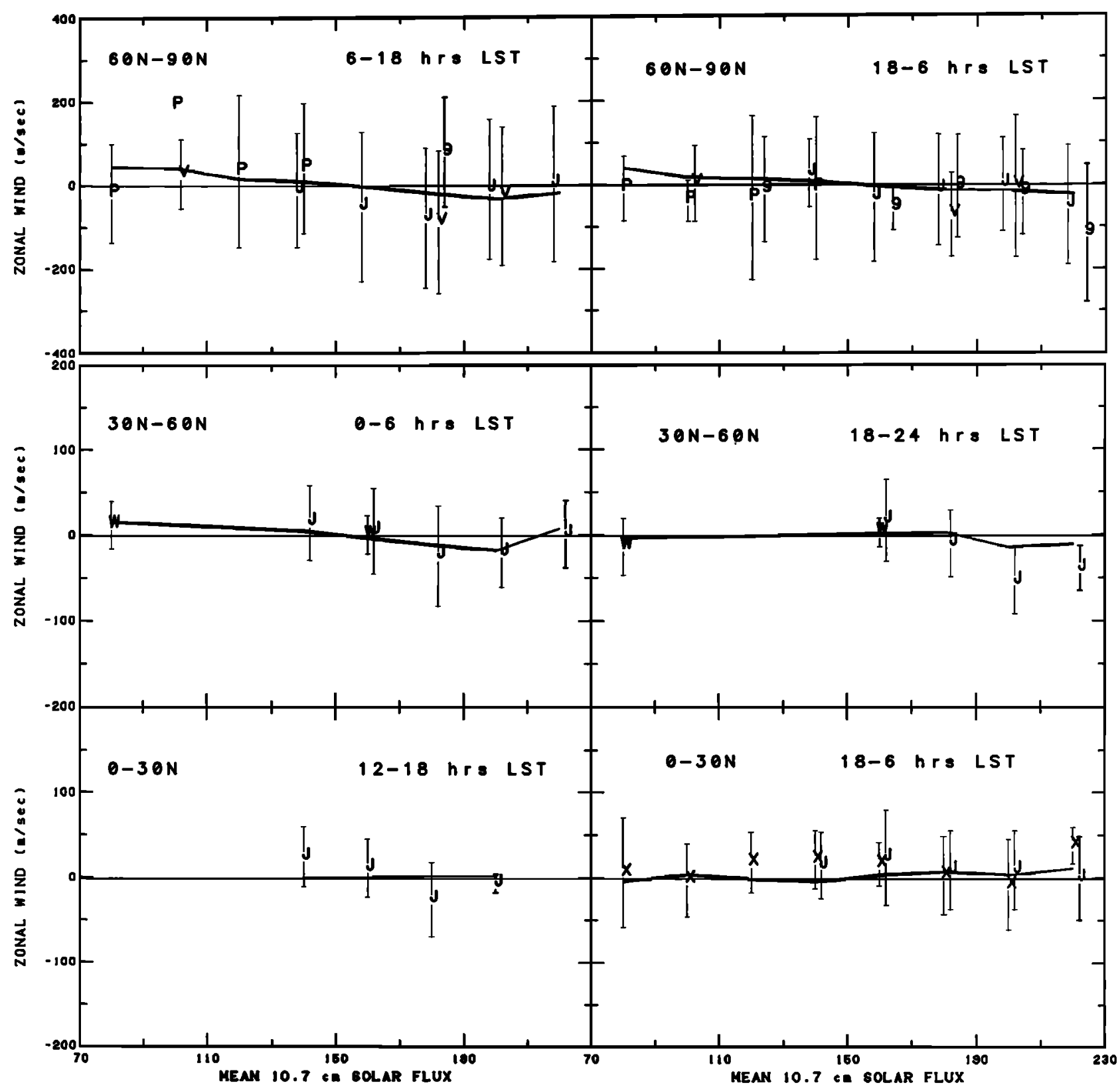

Fig. 28. Measured zonal winds minus HWM90 model winds without solar activity terms averaged in 20 unit bins versus $10.7-\mathrm{cm}$ flux index for data taken between 200 and $350 \mathrm{~km}$ and in three latitude groups with corresponding HWM90 model predictions connected by solid lines. The plot symbols indicate data source as in Figure 2.

\section{References}

Amayenc, P., Tidal oscillations of the meridional neutral wind at midlatitudes, Radio Sci., 2, 281-293, 1974.

Bates, D. R., Some problems concerning the terrestrial atmosphere above the $100 \mathrm{~km}$ level, Proc. R. Soc. London, Ser. A, 253, 451-462, 1959.

Behnke, R. A., and R. M. Harper, Vector measurements of F region ion transport at Arecibo, J. Geophys. Res, 78, 8222-8234, 1973.

Bernard, R., Tides in the E-region observed by incoherent scatter over Saint Santin, J. Atmos. Terr. Phys., 36, 1105$1120,1974$.

Biondi, M. A., J. W. Meriwether, Jr., B. G. Fejer, and S. A.
Gonzalez, Seasonal variations in the equatorial thermospheric wind measured at Arequipa, Peru, J. Geophys. Res., 95, 12,243-12,250, 1990.

Burnside, R. G., and C. A. Tepley, Optical observations of thermospheric neutral winds at Arecibo between 1980 and 1987, J. Geophys. Res., 24, 2711-2716, 1989.

Burnside, R. G., C. A. Tepley, and V. B. Wickwar, The $\mathrm{O}^{+-O}$ collision cross-section: Can it be inferred from aeronomical measurements?, Ann. Geophys. Ser. A, 5, 343-350, 1987.

Cocks, T. D., and F. Jacka, Daytime thermospheric temperatures, wind velocities and emission intensities derived from ground based observations of the OI $630 \mathrm{~nm}$ airglow line profile, J. Atmos. Terr. Phys., 41, 409-415, 1979. 
Groves, G. V., Wind models from 60 to $130 \mathrm{~km}$ altitude for different months and latitudes, J. Br. Interplanet. Soc., 22 , 285-307, 1969.

Harper, R. M., Tidal winds in the 100 - to $200-\mathrm{km}$ region at Arecibo, J. Geophys. Res. 82, 3243-3250, 1977.

Harper, R. M., R. H. Wand, C. J. Zamlutti,and D. T. Farley, $\mathrm{E}$ region ion drifts and winds from incoherent scatter measurements at Arecibo, J. Geophys. Res., 1ㅣ, 25-37, 1976.

Hays, P. B., T. L. Killeen, and B. C. Kennedy, The FabryPerot interferometer on Dynamics Explorer, Space Sci. Instrum., 5, 395-416, 1981.

Hedin, A. E., MSIS-86 thermospheric model, J. Geophys. Res., 92, 4649-4662, 1987.

Hedin, A. E., N. W. Spencer, and T. L. Killeen, Empirical global model of upper thermosphere winds based on Atmosphere and Dynamics Explorer satellite data, J. Geophys. Res., 93, 9959-9978, 1988.

Hernandez, G., and R. G. Roble, The geomagnetic quiet nighttime thermospheric wind pattern over Fritz Peak observatory during solar cycle minimum and maximum, $\underline{\mathbf{J}}$. Geophys. Res., 89, 327-337, 1984.

Jacka, F., A. R. D. Bower, and P. A. Wilksch, Thermospheric temperatures and winds derived from OI $630 \mathrm{~nm}$ night airglow line profiles, J. Atmos. Terr. Phys., 41, 397-407, 1979.

Johnson, R. M., V. B. Wickwar, R. G. Roble, and J. G. Luhmann, Lower-thermosphere winds at high latitude: Chatanika radar observations, Ann. Geophys. Ser. A, $\underline{5}$, 383-404, 1987.

Manson, A. H., C. E. Meek, M. Massebeuf, J. L. Fellous, W. G. Elford, R. A. Vincent, R. L. Craig, R. G. Roper, S. Avery, B. B. Balsley, G. J. Fraser, M. J. Smith, R. R. Clark, S. Kato, T. Tsuda, and E. Ebel, Mean winds of the upper middle atmosphere $(60-110 \mathrm{~km})$ : A global distribution from radar systems (M.F., Meteor, VHF), Handb. MAP, 16, edited by K. Labitzke, J. J. Barnett, and B. Edwards, pp. 239-268, SCOSTEP, Urbana, Ill., 1985.

Meriwether, J. W., Jr., and P. Shih, On the nighttime signatures of thermospheric winds observed at Sondrestrom, Greenland, as correlated with interplanetary magnetic field parameters, Ann. Geophys. Ser. A, 5, 329336, 1987.

Meriwether, J. W., Jr., P. Shih, T. L. Killeen, V. B. Wickwar, and R. G. Roble, Nighttime thermospheric winds over Sondre Stromfjord, Greenland, Geophys. Res. Lett., 11, 931-934, 1984.

Meriwether, J. W., Jr., J. W. Moody, M. A. Biondi, and R. G. Roble, Optical interferometric measurements of nighttime equatorial thermospheric winds at Arequipa, Peru, L. Geophys. Res., 91, 5557-5566, 1986.

Miller, K. L., A. E. Hedin, P. J. Wilkinson, D. G. Torr, and P. L. Richards, Neutral winds derived from IRI parameters and from the HWM87 wind model for the Sundial Campaign of September, 1986, Adv. Space Res., 10(8), 99-102, 1990.

Morse, P. M., and H. Feshbach, Methods of Theoretical Physics, McGraw-Hill, New York, 1953.

Rishbeth, H., Thermospheric winds and the F-region: A review, J.Atmos. Ter. Phys. 34, 1-47, 1972.

Salah, J. E., and J. M. Holt, Midlatitude thermospheric winds from incoherent scatter radar and theory, Radio Sci., 9 , 301-313, 1974.

Schunk, R. W., and J. C. G. Walker, Theoretical ion densities in the lower ionosphere, Planet. Space Sci., 21, 18751896, 1973.

Sica, R. J., M. H. Rees, G. J. Romick, G. Hernandez, and R.
G. Roble, Auroral zone thermospheric dynamics, 1, Averages, J. Geophys. Res., 91, 3231-3244, 1986a.

Sica, R. J., M. H. Rees, R. G. Roble, G. Hernandez, and G. J. Romick, The altitude region sampled by ground-based Doppler temperature measurements of the OI $15867 \mathrm{~K}$ emission line in aurorae, Planet. Space Sci., 5, 483-488, $1986 \mathrm{~b}$.

Smith, R. W., and P. J. Sweeney, Winds in the thermosphere of the northern polar cap, Nature, 284, 437-438, 1980.

Spencer, N. W., H. B. Niemann, and R. R. Carignan, The neutral atmosphere temperature instrument, Radio Sci. 8 , 284-296, 1973.

Spencer, N. W., L. E. Wharton, H. B. Niemann, A. E. Hedin, G. R. Carignan, and J. C. Mauer, The Dynamics Explorer wind and temperature spectrometer, Space Sci. Instrum., 5, 417-428, 1981.

Virdi, T. S., and P. J. S. Williams, Observations of tidal modes in the lower thermosphere using EISCAT, Adv. Space Res., 2(5), 83-86, 1989.

Wand, R. H., Seasonal variations of lower thermospheric winds from the Millstone Hill incoherent scatter radar, $\mathbf{J}$. Geophys. Res., 88, 9227-9241, 1983.

Wardill, $P$., and F. Jacka, Dynamics of the thermosphere over Mawson, Antarctica, III, Horizontal divergence of the wind field, Aust. Natl. Antarct. Res. Exped. Res. Notes, 48, 131-137, 1987.

Wickwar, V. B., Thermospheric neutral wind at $-39^{\circ}$ azimuth during the daytime sector at Sondrestrom, Geophys. Res. Lett., 11, 927-930, 1984.

Wickwar, V. B., Global thermospheric studies of neutral dynamics using incoherent scatter radars, Adv. Space Res. 9(5), 87-102, 1989.

Williams, P. J. S., and T. S. Virdi, EISCAT observations of tidal modes in the lower thermosphere, J. Atmos. Terr. Phys., 51, 569-577, 1989.

M. A. Biondi, Department of Physics and Astronomy, University of Pittsburgh, PA 15260.

R. G. Burnside, Arecibo Observatory, P.O. Box 995, Arecibo, PR 00613 .

A. E. Hedin, Planetary Atmospheres Branch, Code 914,

NASA Goddard Space Flight Center, Greenbelt, MD 20771.

G. Hernandez, Graduate Program in Geophysics, AK-50,

University of Washington, Seattle, WA 98195.

R. M. Johnson and T. L. Killeen, Space Physics Research

Laboratory, University of Michigan, 2455 Hayward Street,

Ann Arbor, MI 48109.

C. Mazaudier, CRPE, 4 Avenue de Neptune, 94107 Saint-

Maur, France.

J. W. Meriwether, AFGL, Hanscom Air Force Base,

Bedford, MA 01731.

J. E. Salah, Massachusetts Institute of Technology,

Haystack Observatory, Westford, MA 01886.

R. J. Sica, Department of Physics, The University of

Western Ontario, London, Ontario, Canada N6A 3K7.

R. W. Smith, Geophysical Institute, University of Alaska,

Fairbanks, AK 99775.

N. W. Spencer, NASA Goddard Space Flight Center,

University Research Foundation, Greenbelt, MD 20771. T. S. Virdi, Physics Department, University College of

Wales, Aberystwyth, Dyfed SY23 3BZ, Wales. 84322 . V. B. Wickwar, CASS, Utah State University, Logan, UT

(Received September 5, 1990; revised December 7, 1990; accepted January 14, 1991.) 